\title{
Oil and the Macroeconomy in a Changing World: A Conference Summary
}

\author{
Christopher L. Foote and Jane S. Little
}

\begin{abstract}
:
Analysis of oil-price movements is once again an important feature of economic policy discussions. To provide some background for this analysis, this paper summarizes a conference on the oil market held at the Federal Reserve Bank of Boston in June 2010. Four cross-cutting themes emerged from this symposium, which included scientific experts, market participants, business leaders, academics, and policymakers. First, the decline in real oil prices that followed the 1970s' oil shocks is unlikely to be repeated today, because there are fewer ways in which oil-importing countries can reduce oil demand or expand domestic supplies in response to higher prices. The second lesson of the conference, however, is that any prediction about oil markets is highly uncertain, a fact illustrated by the wide confidence intervals that result when futures-market data are used to quantify forecast uncertainty. Third, there is little consensus on whether new financial investment in commodity index funds has increased the volatility of oil prices. Finally, changes in oil prices still have large effects on the economy. Some research suggests that the rapid run-up in oil prices in 2007-08 may have significantly weakened the U.S. economy in the early stages of the Great Recession.
\end{abstract}

\section{JEL Classifications: L71, Q4, Q5}

Christopher L. Foote is a senior economist and policy advisor in the research department of the Federal Reserve Bank of Boston. His email addresses is chris.foote@bos.frb.org. Jane S. Little has retired after many years of service with the Federal Reserve Bank of Boston. At the time this conference was held she was a senior economist and policy advisor in the research department at the Federal Reserve Bank of Boston.

This paper, which may be revised, is available on the web site of the Federal Reserve Bank of Boston at http://www.bostonfed.org/economic/ppdp/index.htm.

In addition to all of the conference participants, we thank Jeff Fuhrer and Suzanne Lorant for helpful comments. The views expressed in this paper are those of the authors and not necessarily those of the Federal Reserve System or the Federal Reserve Bank of Boston.

This version: June 2011 


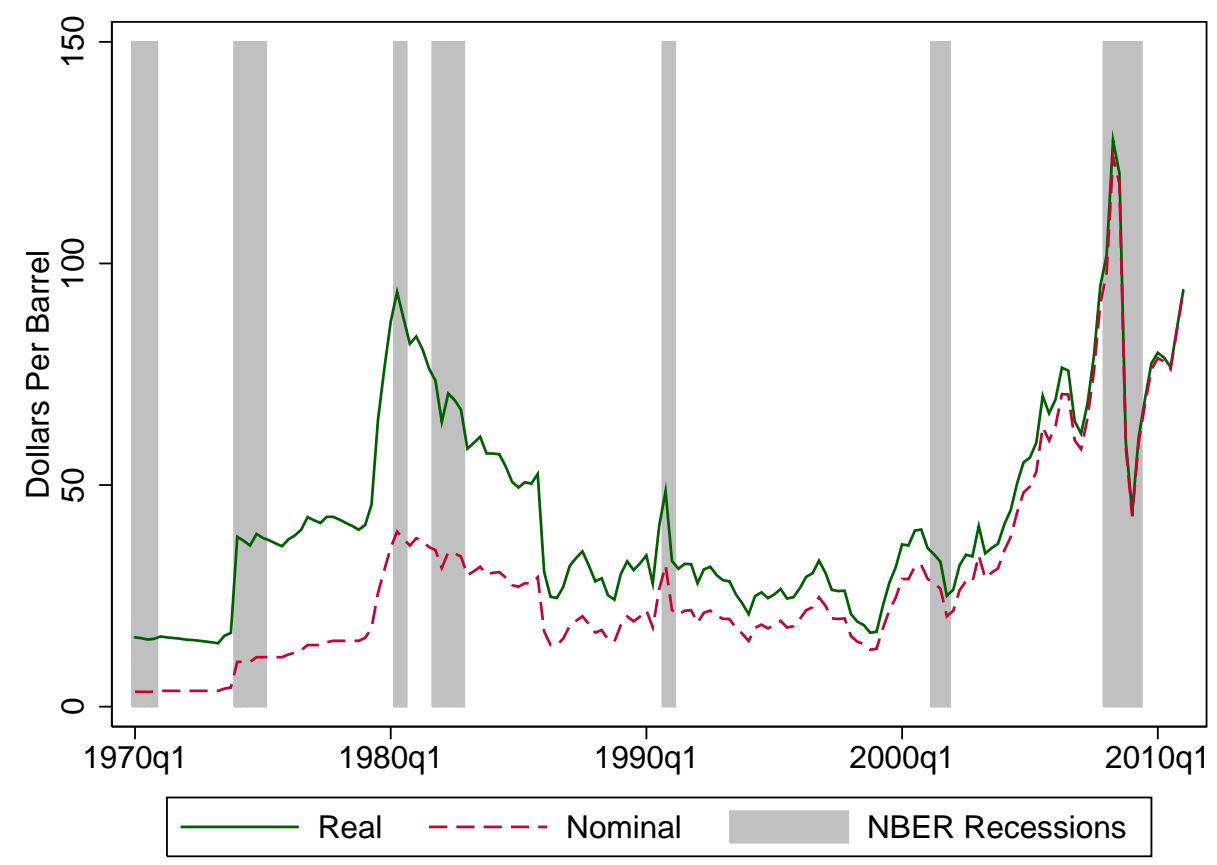

Figure 1. Nominal and Real Prices of West Texas Intermediate Crude Oil: 1970:Q1 to 2011:Q1. Posted prices are used prior to 1982. The GDP deflator is used to transform the nominal oil price into a real price (2011:Q1 dollars). Sources: Wall Street Journal, Bureau of Economic Analysis, and National Bureau of Economic Research.

\section{Introduction}

Oil prices have gyrated significantly over the past decade. As shown in Figure 1, a barrel of West Texas Intermediate crude oil sold for just under $\$ 30$ in early 2001. After a dip during the 2001 recession, oil prices began a sustained increase that took them near $\$ 75$ per barrel by mid-2006. Soon after, the price increase accelerated, with prices topping out at more than $\$ 145$ per barrel in July 2008. The onset of the Great Recession helped send prices sharply lower, as a barrel of oil averaged about $\$ 43$ in the first quarter of 2009 . The recovery from the recession, combined with concern over potential supply disruptions in Libya and other oil producers, has sent prices higher again this year. Prices broached the $\$ 100$ mark in March and rose to $\$ 112$ in April, before falling back to about $\$ 100$ in early May.

Price movements like these have long been of interest to economic policymakers. Figure 1 also shows that rising oil prices have typically preceded recessions, an empirical regularity that has remained consistent since it was formally documented in Hamilton (1983). Yet the economic effects of oil are hard to explain in simple economic models, because oilbased products account for a small share of consumer and business spending. Moreover, as stressed by Boston Fed President Eric Rosengren in his opening remarks, the reasons behind oil-price movements have often baffled observers. Rising demand from emerging 
markets like India and China might have accounted for $\$ 145$ oil in 2008 - but what about the collapse in prices over the subsequent seven months? Could oil-market "fundamentals" be behind both movements, or did a speculative boom-bust cycle in the oil market also play a role?

To help answer such questions, the Federal Reserve Bank of Boston held an interactive symposium, Oil and the Macroeconomy in a Changing World, on June 9, 2010. The conference gathered scientific experts, market participants, business leaders, academics, and policymakers for discussions that covered many facets of the oil market. Among other topics, participants debated the likely short- and long-run outlooks for oil supply and demand, the best ways to model oil prices, the reasons for oil's outsized effect on GDP, and the effect that potential climate-change legislation might have on the oil market. The symposium was "presentation-based," in that no formal papers were submitted or presented. Rather, each session featured an expert presentation on a particular topic, followed by remarks from a discussant and then an open conversation among all attendees. ${ }^{1}$

In this paper, we summarize this conference by presenting synopses of the individual sessions. Our goal is to provide some background for the analysis of current oil-price movements. But before describing the conference sessions individually, we outline four crosscutting themes that came up often throughout the day.

\subsection{High oil prices are (probably) here to stay}

As would be expected, many discussions concerned the outlook for oil prices. As shown in Figure 1, the real price of oil trended lower in the decades following the 1970s' oil shocks. Unfortunately, conference participants generally believed that a similar decline is unlikely to occur after recent oil-price increases. The 1980s' decline owed much to the way in which advanced economies responded to higher oil prices. But similar responses along either the demand or supply margins are less likely today.

On the demand side, the 1970s' shocks encouraged advanced economies to reduce oil use in areas like electric-power generation, where coal or nuclear alternatives were available. These responses mean that today, the easiest substitutions out of oil have already been made, so there is less scope for further conservation. According to the U.S. Energy Information Administration (EIA), the total amount of energy generated from all liquid fuels is expected to rise modestly in the United States over the next 25 years, after a recent recessionary decline (Figure 2). Most of this liquid fuel will be used in areas where there are now few viable alternatives. In particular, Figure 3 shows that about 70 percent of liquid fuel is

\footnotetext{
${ }^{1}$ The presentations and discussions can be accessed at the conference website: http://www.bostonfed. org/economic/conf/oil2010/index.htm.
} 


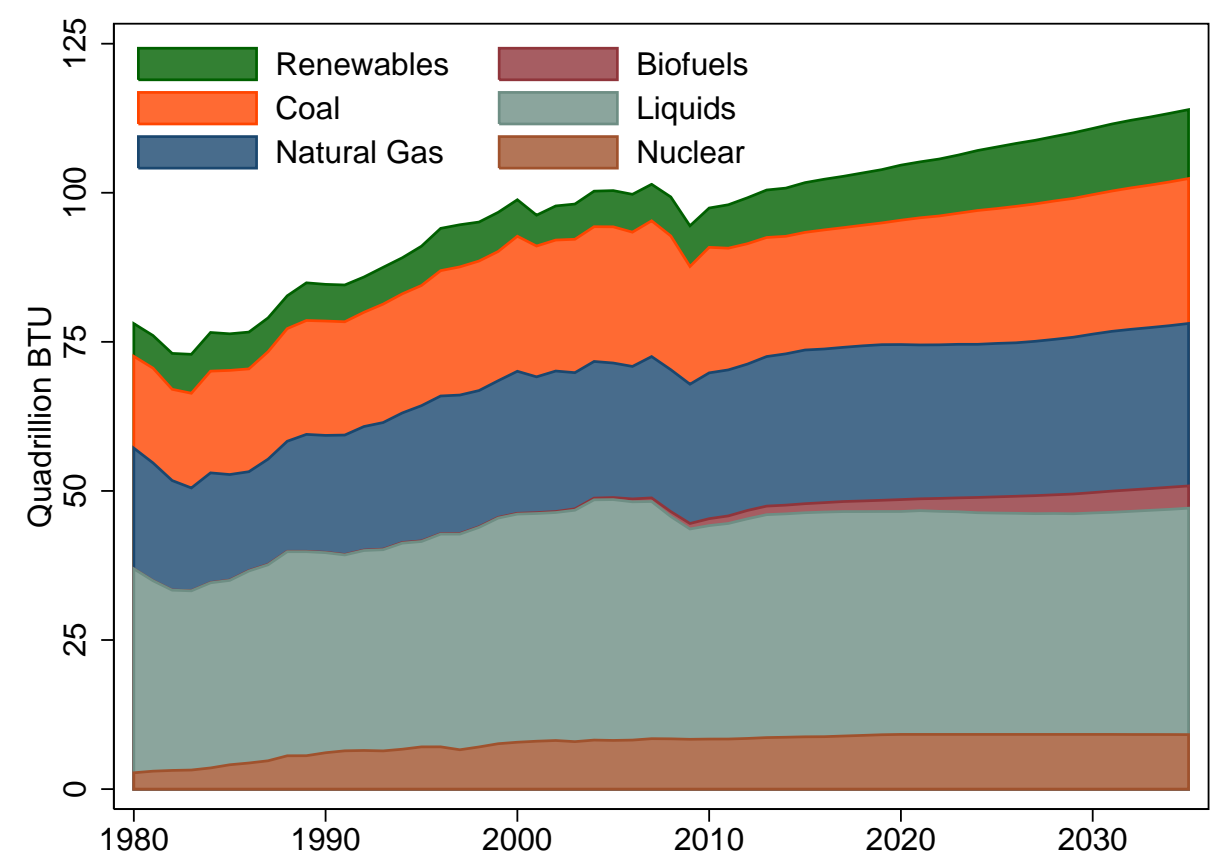

Figure 2. Primary Energy Use by Fuel (History and Projections). Source: Energy Information Administration, 2011 Annual Energy Outlook, Fig. 57.

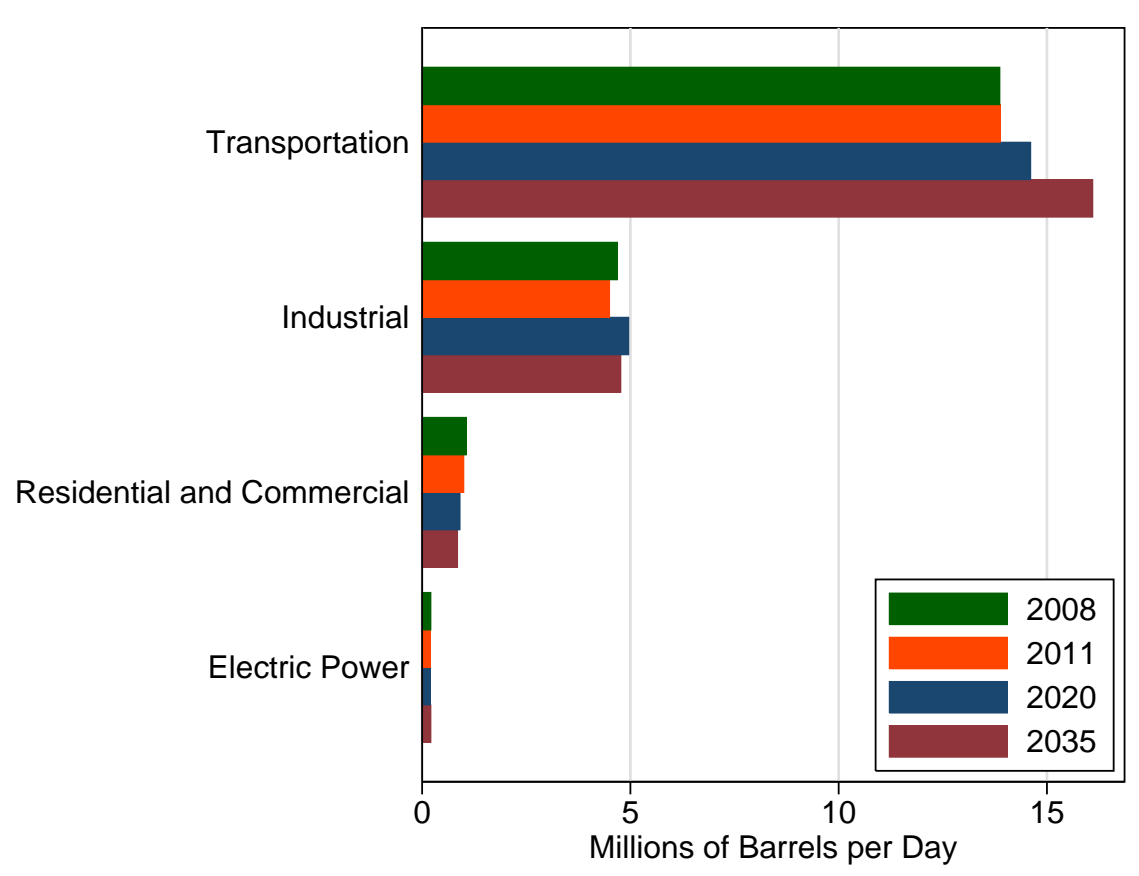

Figure 3. Use of Liquid Fuel in the United States by Sector in Selected Years (History and Projections). Source: Energy Information Administration, 2011 Annual Energy Outlook, Fig. 93. 


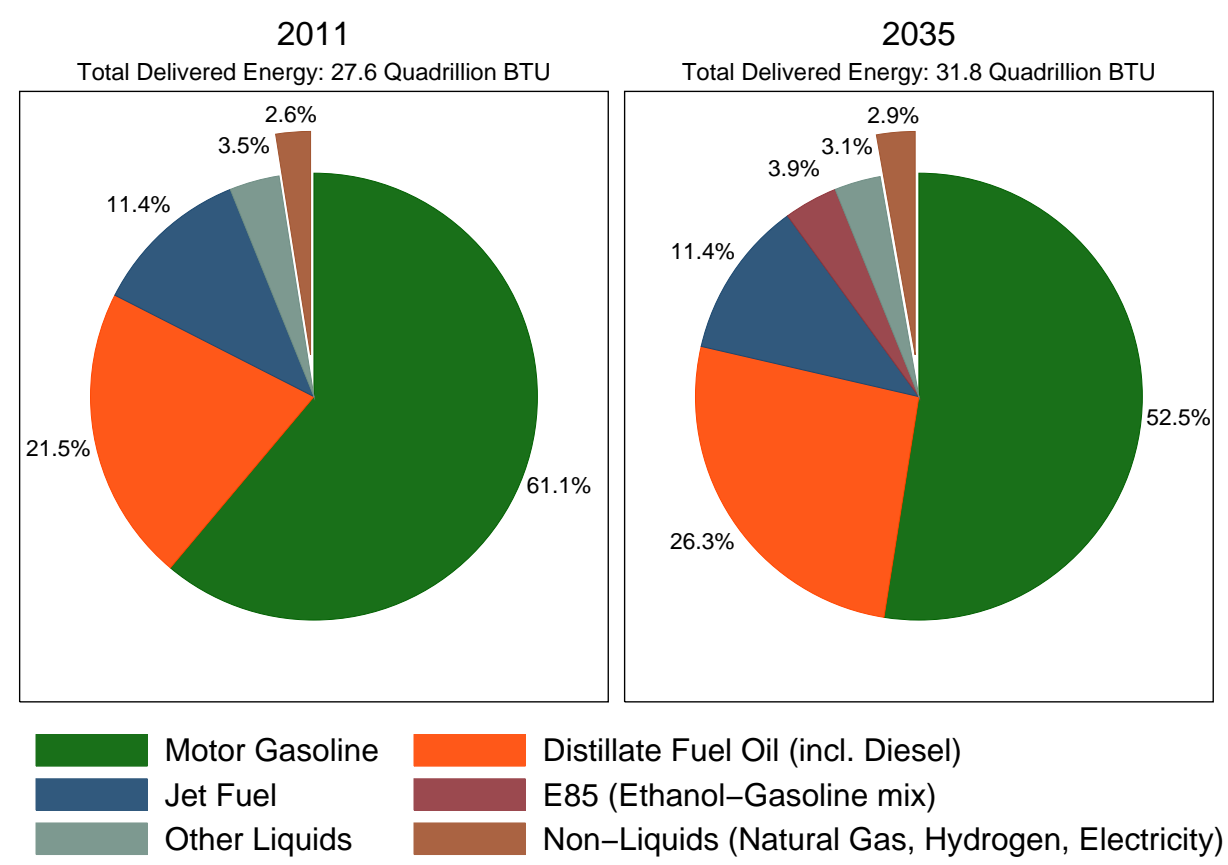

Figure 4. Energy Shares for the U.S. Transportation Industry in 2011 and 2035 (Projected). Source: Energy Information Administration, 2011 Annual Energy Outlook, Table A2.

used in the transportation sector, which requires energy-dense and transportable sources of power. ${ }^{2}$ The close relationship between the transportation sector and oil-based fuels is also apparent in Figure 4, which shows that liquid fuels will supply all but 2.6 percent of the energy for transportation this year. To be sure, over the next quarter-century, the EIA expects significant growth in the use of oil alternatives, such as ethanol and compressed natural gas. But a number of issues complicate the development and extensive use of alternative transportation fuels, including the high direct costs of developing and using non-oil fuels and the difficulty of switching the nation's fueling infrastructure to a non-oil source. As a result, the EIA expects that in 2035, transportation energy will be mostly supplied by oil-based fuels such as motor gasoline, diesel fuel, and jet fuel - just as it is today.

While oil will remain the main source of power for the U.S. transportation sector, the total energy demands of this sector are not expected to grow much over the long term. As shown in the subheadings of Figure 4, transportation energy use is expected to rise from 27.6 to 31.8 quadrillion BTU over the next quarter-century, suggesting an annual rate of increase that is much lower than most estimates of potential GDP growth. The growth-rate difference stems from the already-mechanized state of the U.S. transportation

\footnotetext{
"Future-year projections for all of the figures in this section come from the EIA's "Reference Case" estimates for 2011, as published in EIA's 2011 Annual Energy Outlook. The EIA also supplies some alternative projections, which are discussed in subsequent sections.
} 


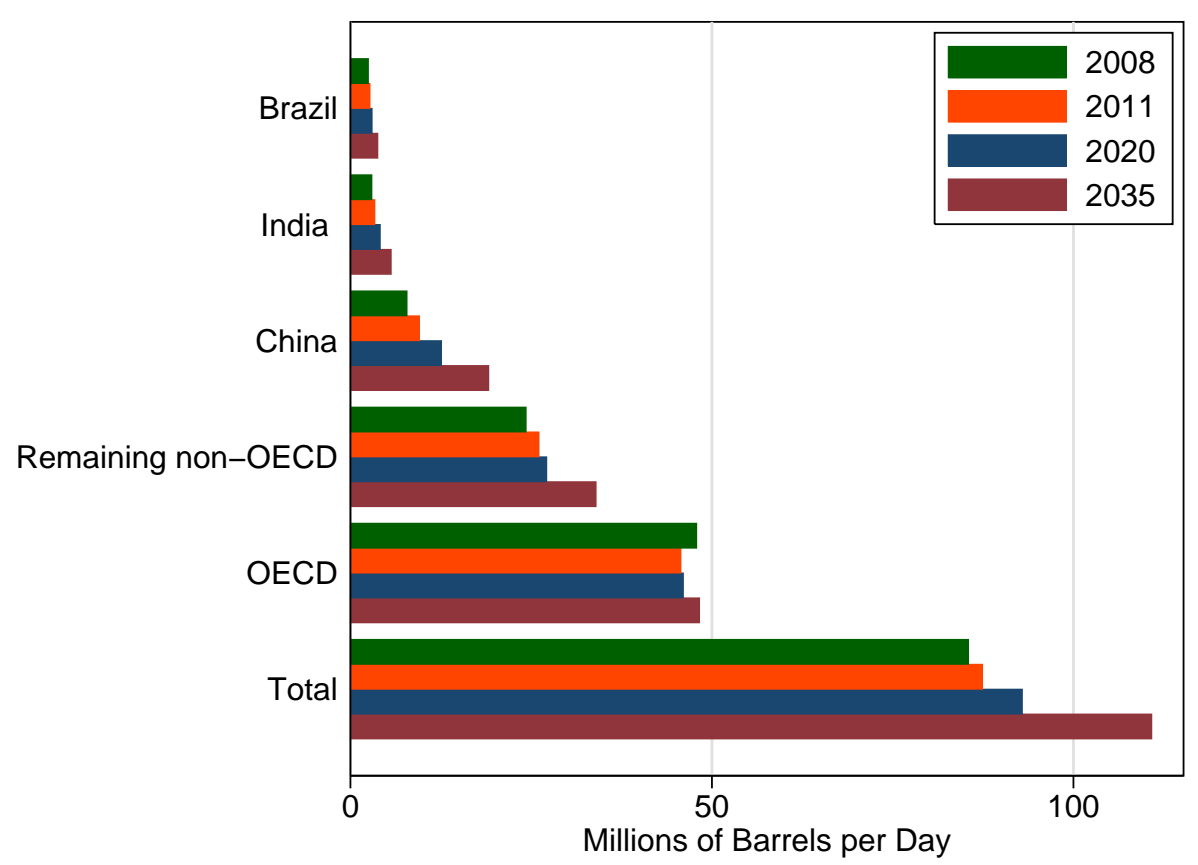

Figure 5. Consumption of Liquid Fuels by Geographical Region in Selected Years (History and Projections). Source: Energy Information Administration, 2011 Annual Energy Outlook, Table A21.

industry as well as from ongoing gains in energy efficiency. But energy needs will grow faster in other countries. Figure 5 presents the EIA's forecasts for consumption of liquid fuels in various geographical regions through 2035. This figure illustrates the rapid growth of demand emanating from industrializing countries such as India and China, which are close to development levels where energy demands rise rapidly (moving up the so-called "energy ladder"). In particular, Chinese liquid-fuel demand is expected to approximately double by 2035. Consequently, even though liquid-fuel demand for the advanced countries of the OECD is expected to be stable, the EIA projects that overall world demand for liquid fuel will experience cumulative growth of more than 25 percent over the next 25 years. ${ }^{3}$

On the supply side, advanced economies expanded their production of oil after the 1970s' oil shocks, developing hard-to-reach oil fields in the North Sea and Alaska. But the general view of conference participants was that a similar supply response is less likely today. Figure 6 shows that U.S. oil production is expected to grow somewhat, especially over the next several years, while oil imports trend lower. At the same time, as suggested by Figure 4, the production of alternative liquid fuels, including biofuels, should grow sharply from a small base. But conference participants generally believed that the total liquids production of OECD countries would not grow significantly in the future, so oil imports to advanced

\footnotetext{
${ }^{3}$ The OECD is the Organisation for Economic Cooperation and Development, a Paris-based collection of 34 generally advanced economies.
} 


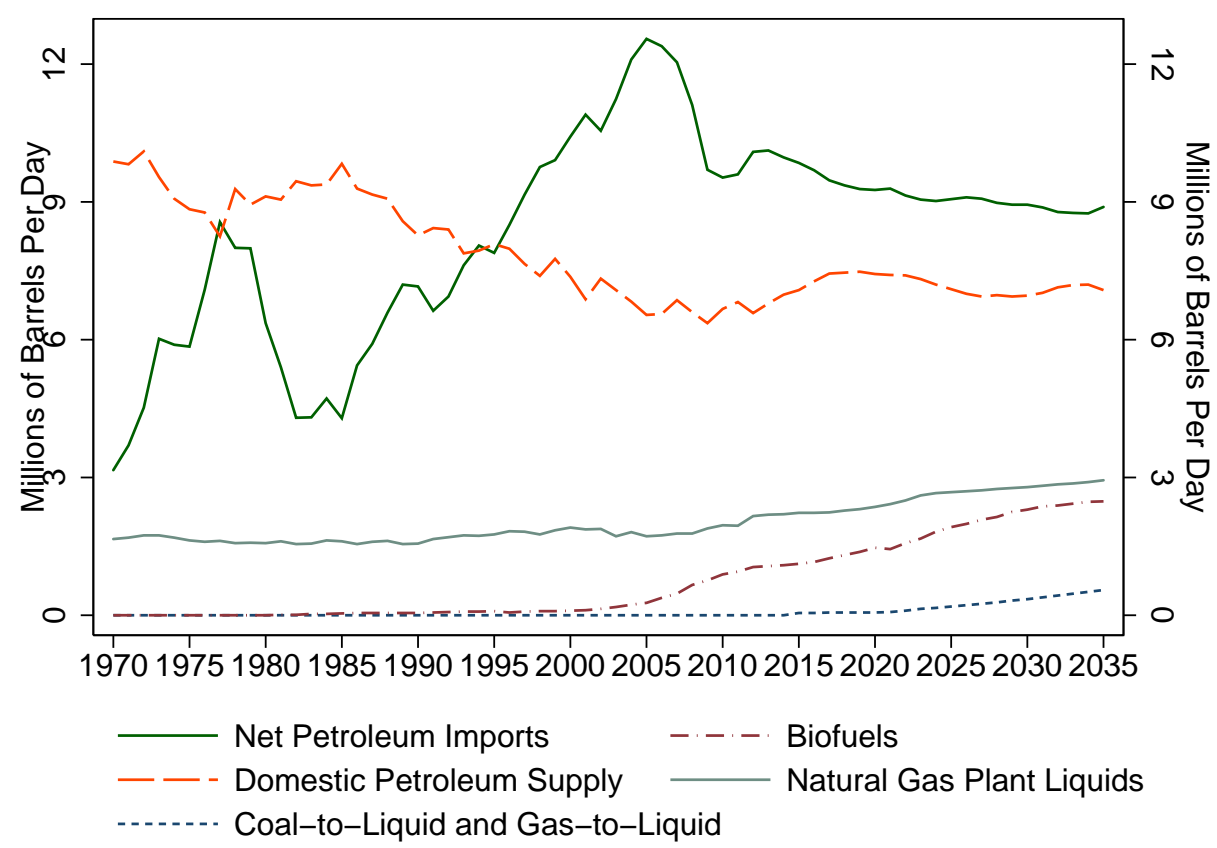

Figure 6. Components of the U.S. Liquid Fuel Supply in Selected Years (History and Projections). Source: Energy Information Administration, 2011 Annual Energy Outlook, Fig. 1.

economies will remain high. In particular, Figure 6 shows that the EIA expects the U.S. to import close to nine million barrels of oil each day over the next 25 years.

Taken together, these facts argue against a sustained decline in real oil prices like that of the 1980s. Advanced economies have already exploited the easiest ways to reduce oil demand and expand domestic supplies. Few participants at the conference believed that the world had reached the period of "peak oil," after which world oil production would actually shrink. But rising global demand for oil and the lack of a significant supply response from advanced countries places a great deal of market power in countries that can expand oil production cheaply, in particular the OPEC nations. ${ }^{4}$ Of course, oil prices would fall if OPEC decided to pump more oil. As explained by Howard Gruenspecht, the Deputy Administrator of the EIA, real oil prices could plummet to near $\$ 50$ per barrel if OPEC decided to raise its share of the global liquids market from 40 to near 50 percent. But relative to the 1980s, changes in world oil demand and supply patterns are less likely to put independent pressure on the OPEC cartel to increase production. Oil prices are therefore expected to remain high for the next quarter-century.

\footnotetext{
${ }^{4}$ OPEC stands for the Organization of the Petroleum Exporting Countries, which now has 12 members. The five countries that founded OPEC in September 1960 were Iran, Iraq, Kuwait, Saudi Arabia, and Venezuela. Countries joining OPEC later included Qatar (1961), Indonesia (1962), Libya (1962), the United Arab Emirates (1967), Algeria (1969), Nigeria (1971), Ecuador (1973), Gabon (1975), and Angola (2007). Gabon terminated its membership in 1995 and Indonesia suspended its membership in 2009.
} 


\subsection{Predictions for oil prices are uncertain at all time horizons}

The prediction that oil prices will remain high is just that - a prediction, representing the best guess about the future but not a statement of fact. Indeed, as the conference title suggests, today's oil market operates in a rapidly changing world, so any predictions about this market are highly uncertain. Much of this uncertainty stems from the close relationship between oil and the transportation sector. In the short run, the lack of alternatives to oil as a source of transportation energy mean that large changes in oil prices are required to restore equilibrium when oil supply is disrupted or when oil demand increases. Because oil markets are forward-looking, prices typically rise even when the world's spare oil-production capacity starts to run low. ${ }^{5}$

One way to quantify the degree of short-run uncertainty is to use data from futures markets to construct confidence bands around oil-price forecasts. Futures markets allow hedgers and speculators to determine prices for future oil deliveries, based on their forecasts for supply and demand. Because prices in futures markets are so flexible, most experts believe that "price discovery" in the oil market takes place through futures trading. The current spot price of oil is then determined by working backward from the futures price to the present, making allowances for storage costs and other technical factors. The EIA uses the prices of market-traded options in futures markets to construct confidence bands around its predictions, and these confidence bands turn out to be wide. In May 2011, the EIA's 95-percent confidence interval for the oil price only 18 months ahead ranged from $\$ 60$ to $\$ 200$ per barrel. ${ }^{6}$ The breadth of this interval means that policymakers must consider a wide variety of potential outcomes even in the short run.

Ultimately, the statistical uncertainty surrounding oil-price forecasts reflects the economic and political uncertainties that affect world oil markets. A prime example of economic uncertainty is the world business cycle. When global economic activity contracts, the world's demand for oil contracts as well and oil prices usually fall. For example, Figure 2 shows that U.S. liquid-fuel use dropped sharply during the Great Recession of 2007-09, while Figure 6 shows that much of this decline was experienced as lower oil imports. When extrapolated globally, the sensitivity of oil demand to GDP means that any short-run oil forecast is only as good as the short-run output forecast that underlies it.

The importance of emerging economies in future oil demand means that output forecasts for these countries are particularly important. In particular, a crucial wild card is how quickly the Chinese and Indian economies will grow, or, to put it differently, how quickly

\footnotetext{
${ }^{5}$ Some research on the academic frontier of oil-price forecasting includes Baumeister and Kilian (2011) and Alquist et al. (2011).

${ }^{6}$ Figure 8 below provides a graph of this interval.
} 
those two countries will move up the energy ladder. A new model by Eyal Dvir of Boston College and Kenneth Rogoff of Harvard, discussed by Dvir in the conference's opening session, illustrates how uncertainty about emerging-economy growth rates could affect the oil market (Dvir and Rogoff 2009). The Dvir-Rogoff model assumes that the oil market has limited access to spare production capacity, so demand shocks tend to increase prices rather than raise production. The model also assumes the presence of oil inventories. In this world, a temporary increase in demand encourages traders to sell oil out of inventories today, rather than wait to sell the oil tomorrow. The oil that flows out of inventories after temporary shocks limits their price repercussions. But inventories do not dampen prices when shocks are permanent. As Dvir and Rogoff explain, permanent shocks do not encourage traders to sell oil from inventories, because demand will be high both today and tomorrow. Since the amount of oil sold from inventories does not increase, permanent shocks cause larger increases in oil prices than temporary shocks. Under certain conditions, traders may even increase their inventories when faced with a permanent shock to demand (for example, if they expect demand to grow further in the future). This increased desire for inventories may contribute to increased price volatility.

The question of whether recent oil-price hikes are due to fundamentals or speculation occupied a great deal of discussion at the conference; the Dvir-Rogoff model provides a fundamentals-based explanation for price increases. In particular, the model links price movements to the extremely high growth rates in certain developing economies, as well as high projections for these growth rates in the years to come. In addition, given continued uncertainty about the sustainability of growth rates in the developing world, Dvir and Rogoff's model predicts continued gyrations in oil prices until this uncertainty is resolved, or until easy access to spare oil-production capacity can be restored.

Participants also discussed oil-market uncertainty that arises from the uneven pace of technological advancement. In the future, some scientific breakthrough could allow an oil alternative to meet the test of the market, or reduce the cost of extracting oil from hardto-reach places. But no one knows whether or when such a breakthrough will occur. The technology optimists at the conference included David Hobbs, the Chief Energy Strategist at IHS Cambridge Energy Research Associates. In his session, Hobbs noted that as offshore oil drilling was expanded in the 1960s and 1970s, improvements in technology caused the nominal cost of this development to fall by half in less than a decade. He added that people have worried about the exhaustion of the world's oil supply several times during the past 100 years, but that new technologies have always been developed to deliver the oil that the world required. Other participants were more skeptical, noting the stubborn cost challenges that have plagued the development of alternative fuels. For example, manufacturing liquid fuel 
from biomass or natural gas requires a great deal of energy in the transformation process, reducing the resulting economic benefits. And the main technology used to turn coal to liquid fuel has remained little changed since World War II.

Political factors also generate uncertainty about the oil market. According to the EIA's Gruenspecht, that agency believes that the production decisions of OPEC will essentially determine the long-run future of oil prices. But OPEC decisions may be influenced more by political goals than by the maximization of profit. More generally, a striking change in the oil market during the past four decades is that a great deal of oil has fallen under the control of national oil companies (NOCs), which are controlled by their home-country governments. Gruenspecht noted that in 1970, fully 85 percent of world oil reserves were controlled by international oil companies (IOCs). By 2009, however, 65 percent of oil reserves were NOC reserves that had only limited IOC control. Moreover, some of these NOCs exert an outsized influence on oil markets, because they are among the small number of oil producers with access to high-quality, easily accessible oil.

Because NOCs might further their governments' political goals rather than maximize profits over the long term, predicting their behavior is difficult. John Deutch, an Institute Professor at MIT and a former Director of the U.S. Central Intelligence Agency, highlighted the potential for geopolitical strains in the oil market in his remarks. He said that Iran in particular has been able to fend off concerted international pressure thanks to its muchneeded oil production. He added that NOCs have a tendency to enter bilateral, state-tostate relationships with other countries that are not transparent to outside observers, and he warned that these developments could lead to "serious conflict" between nations in the years ahead.

Another source of political uncertainty concerns the potential for climate-change legislation. Many participants noted that an efficient climate-change policy would have little direct effect on the oil market - a point that is often omitted from popular discussions of climate-change legislation. An efficient carbon policy would equalize the cost of reducing emissions across all carbon sources. Because emissions have already been reduced a great deal in the transportation sector, further reductions there are more expensive than reductions in emissions from coal. "A climate policy, if it is cost-effective, is essentially a tax on coal," said Robert Stavins of Harvard's Kennedy School of Government, an expert on climate policy, who delivered lunchtime remarks. In particular, Stavins said that a climate policy that gradually reduced emissions by 83 percent below 2005 levels by 2050 might raise coal prices by 250 to 300 percent by 2030 , yet have only minor direct effects on the oil market. That said, Stavins and other participants noted that politically feasible climate-change policies might not be efficient in the economic sense. One possibility discussed by Stavins 
was a "cap-and-trade plus/minus" policy, which would combine a standard cap-and-trade system with more stringent fuel-economy standards for cars and trucks. The fuel-economy standards would reduce carbon emissions at a higher social cost than the social cost of a policy that would raise the price of gasoline. But Stavins said that this cost would be less visible to consumers and therefore more politically palatable to legislators.

\subsection{There is little consensus on whether the "financialization" of oil has affected oil prices}

Taken together, economic and political uncertainties in the oil market provide a framework for explaining the oil-price gyrations of recent years. The Dvir-Rogoff model explains how relatively permanent changes in oil demand arising from emerging countries like China or India could have big effects on oil prices, as long as the world's access to spare capacity is limited. Yet some participants were unwilling to ascribe all of the recent volatility of oil prices to fundamental forces. Financial speculation in oil markets could have contributed to oil-price hikes in the 2000s by driving prices higher in a classic asset-market bubble. In his remarks, Bart Chilton, a commissioner of the U.S. Commodity Futures Trading Commission (CFTC), noted that about $\$ 200$ billion of financial investment entered oil markets during the mid-2000s' run-up in oil prices. Much of this investment came from what Chilton called "massive passive" funds, which expose investors to oil prices via a price-indifferent, buyand-hold trading strategy. Recent research has indicated that exposure to commodity prices could be attractive to investors seeking diversification of their financial portfolios (Gorton and Rouwenhorst 2006). However, Chilton said that the sheer size of these investments provides a prima facie case for concern. In addition, Chilton argued that regulators need more information about over-the-counter and futures-market activities of oil traders: he spoke approvingly of legislation then moving through Congress to enhance the informationgathering and enforcement powers of regulatory agencies. This legislation, now called the Dodd-Frank Wall Street Reform and Consumer Protection Act, was signed into law by President Obama on July 21, 2010, six weeks after the conference took place. The new law also instructs the CFTC to issue position limits in the oil-futures market, which would limit the size of individual investments in that market. ${ }^{7}$

The discussant for Commissioner Chilton's comments was James Overdahl, a vice president of NERA Consulting, Inc., and the former chief economist of both the CFTC and the Securities and Exchange Commission. Overdahl said the jury was still out as to whether

\footnotetext{
${ }^{7}$ The CFTC has long had position limits in the agricultural futures market and was investigating the possibility of issuing position limits for energy trading when the Dodd-Frank Act passed.
} 
new investment had driven oil prices higher. He stressed that the new financial investment in oil was not "hot money" seeking out short-term gains, but rather index-based investments looking for financial diversification. Overdahl also referenced a small but growing body of academic work that tries to identify the effect of the investment flows on prices. One finding in this literature is that the investment positions of various types of investors seem to follow price movements, suggesting that investors were responding to prices rather than exerting undue influence over them (Interagency Task Force on Commodity Markets 2008; Harris and Buyuksahin 2009). Additionally, Overdahl said that some of his own research suggests that additional futures investment had deepened futures markets, so that the prices of contracts at various horizons moved more closely together. Additionally, the increased depth in markets for longer-dated contracts has enhanced price discovery in these markets, while also lowering the cost of using long-term contracts to hedge against risk (Buyuksahin et al. 2008).

Other research presented at the conference spoke directly to the role of speculation in oil markets. Lutz Kilian, an economics professor at the University of Michigan who writes frequently on oil issues, presented some joint work with Daniel Murphy that attempts to quantify the importance of three types of shocks to the oil market (Kilian and Murphy 2010). A "flow demand shock" reflects fluctuations in global business activity. A "flow supply shock" resembles a traditional supply shock, of which the outbreak of the IranIraq war in 1980 might be one example. Finally, a "speculative demand shock" raises the demand for above-ground oil inventories due to shifts in expectations about future supply and demand conditions. ${ }^{8}$ Kilian and Murphy find that speculative-demand shocks have occasionally disrupted the oil market, most notably in 1979, 1986, and 1990. But they find little role for speculative-demand shocks during the mid-to-late 2000s. Instead, their model implies that an unexpectedly booming world economy drove the demand for oil higher during this episode.

All told, participants heard a variety of perspectives on the role of speculation and financial-market innovation on the oil market. While rapidly growing oil demand from emerging markets and an uncertain supply picture are consistent with high prices, many participants were skeptical that recent price movements could be completely explained by fundamental forces. ${ }^{9}$ Consensus on the role of speculation in the oil market will depend on additional research.

\footnotetext{
${ }^{8}$ This type of shock might occur if traders believed that oil prices were headed higher, rewarding those who bought oil today to sell at a later date.

${ }^{9}$ As one participant said during the Chilton-Overdahl session, which came before Kilian presented his results, "When crude oil prices ran up to $\$ 140$ or $\$ 150$, it sure didn't look like the fundamentals of supply and demand. It looked like something else was going on."
} 


\subsection{Oil prices still have sizable effects on the economy}

While there was substantial disagreement about financial speculation in oil markets, there was general consensus that oil prices have significants effects on the wider economy. Higher oil prices can slow GDP growth in many ways. On the demand side, higher oil prices force U.S. consumers to remit more of their income abroad to pay for oil imports, leaving less income to be spent on domestically produced goods and services. Higher prices may also heighten economic uncertainty, causing consumers to delay big-ticket, energy-intensive purchases like automobiles. Additionally, if oil-price increases turn out to be permanent, they can engender substantial reallocations of production away from oil-intensive uses. This reallocation can absorb resources that could have been used to produce output.

James Hamilton, an economics professor at the University of California at San Diego who writes frequently on oil and the macroeconomy, focused on how oil-price changes affect the buying decisions and confidence levels of U.S. consumers. Drawing on work by Edelstein and Kilian (2007, 2009), Hamilton presented statistical evidence indicating that consumers reduce the purchases of long-lived durable goods when oil prices rise. This consumption decline reduces GDP directly and can also have long-lasting "multiplier" effects on GDP, if lower vehicle sales reduce the income and consumption of workers in durable-goods industries. These multiplier effects can help explain why oil-price spikes appear to reduce aggregate consumption for months after they occur. In fact, Hamilton showed that the 2007-08 spike in oil prices can potentially explain both the slowdown in economic activity and the decline in consumer sentiment that occurred in the the opening months of the Great Recession, before the Lehman Brothers bankruptcy disrupted the world's financial system. ${ }^{10}$

While econometric evidence suggests that oil prices have wider economic effects, characterizing the response to any particular price movement is difficult in real time. The discussant for Hamilton's presentation was Ethan Harris of Bank of America/Merrill Lynch. Harris discussed the actual response of the economy to six oil-price episodes with which he had practical experience, either as a researcher at the Federal Reserve Bank of New York or later as a Wall Street economist. Harris said that the general lesson from these episodes was that it is hard to find clear, "linear" response rules for how GDP changes when oil prices move. Some evidence suggests that only large oil-price movements may be significant enough to affect GDP. Price changes may also have asymmetric effects, with increases having larger absolute impacts on GDP than decreases. Further, consumption is likely to respond to persistent changes in oil prices differently than to temporary ones, and all consumption responses might be influenced by the historical "frame" in which the price increase occurs. As an example, the oil-price increase of 1990 could have reminded Americans of the twin

\footnotetext{
${ }^{10}$ See also Hamilton (2009) on this point.
} 
oil shocks of the 1970s, Harris said. If so, then the psychological framing of the 1990 shock could explain the steep drop in consumer confidence in that year. Finally, the fundamental difficulty of identifying an oil-supply shock from an oil-demand shock means that the nonlinearity of oil-price responses is not the only complexity facing oil-market analysts. ${ }^{11}$ "The identification problem and the nonlinear-response problem often get linked together," Harris said. "So it's quite a complicated situation in real time."

In the remaining sections of this paper, we review each session of the conference. We then conclude with some outstanding questions that were suggested by conference discussions.

\section{Oil Prices through History: Setting the Scene}

To set the stage for the ensuing sessions, the conference's first session provided some historical perspective on recent oil-price movements. David Hobbs of IHS Cambridge Energy Research Associates began by claiming that the 2008 price spike did not reflect the interaction of growing demand and a geological supply constraint. "The world isn't running out of oil," he said. "Or if it is, it's the fifth time it's done so."

Hobbs argued instead that the 2008 price increase was the latest manifestation of a classic oil-price cycle. Hobbs said that in 2002-03, oil-market participants expected some supply disruption related to the geopolitical tensions between Iraq and the United States. It was hoped, but not certain, that any armed conflict would not inflict significant damage on Iraq's oil infrastructure and would therefore have only short-lived effects on oil prices. What was not expected was that in December 2002, Venezuelan oil workers began a general strike that reduced that country's oil production. The strike, along with a coincident supply disruption in Nigeria, reduced the world's short-run oil supply by an amount that was close to spare-capacity estimates at the time, Hobbs said. The remaining razor-thin capacity margin left the oil market highly vulnerable to another supply disruption, such as might occur in Iraq, or to a positive demand shock.

Unfortunately, that positive demand shock soon emerged from China. Hobbs contended that this increase was over and above the steadily increasing demand arising from Chinese industrialization. Rather, Hobbs explained that the sharp 2003 increase in Chinese oil demand was an "artifact" of decisions of Chinese factory owners, fearing power shortages as a result of delays in the construction of new, coal-fired generating capacity. They purchased a large number of oil-fired generators - enough to burn several hundred thousand barrels of

\footnotetext{
${ }^{11}$ There is a debate in the economic literature regarding the nonlinearity of economic responses to oil prices. See Kilian and Vigfusson (2010) for arguments against nonlinearity and Hamilton (2010) for arguments in favor.
} 
oil each day. The end result, Hobbs said, was that Chinese oil demand grew by one million barrels per day in 2003, an amount that represented fully half of estimated global demand growth at the time. If China's demand growth were extrapolated, that country's demand would rise by at least 20 million barrels over the next two decades. "We ended up with this perception that even if the world is not running out of oil, we couldn't increase supply fast enough to meet this roaring demand," Hobbs said.

The Chinese "demand shock" proved to be short-lived. One year later, the coal-fired power plants came online, obviating the need for their backup generators, and Chinese oil demand fell back to its expected trend. By then, however, a new psychology had gripped the world oil market, Hobbs said. "People had become convinced that there was this new secular demand trend that couldn't possibly be met," Hobbs said. Peak-oil fears also seeped into the popular consciousness. Oil prices began to rise. The higher prices did not seem to slow down the world economy, leading to further speculation that oil prices would be much higher in the new steady state.

Around 2007, the balance between supply and demand began to shift, Hobbs said. Production capacity began to rise, due to new investments launched during the initial period of higher prices three to four years earlier. As would be expected, increased oil production and lower demand in response to high prices caused oil prices to fall. Hobbs argued that the entire cycle was reminiscent of past boom-bust periods that had previously plagued the oil market. "What you see is a classic cycle, caused by a lack of investment early in the cycle, leading to tight markets, leading to oversupplied markets, leading to price collapse," he said.

In a note of optimism, Hobbs predicted that new sources of oil, or new oil-competing technologies, would meet the test of the market in the years to come, just as they had in years past. As an example, he cited the North Sea. "In the 1960s, everyone expected that there was a lot of oil in the North Sea," Hobbs said. "The issue was that it was all going to be far too expensive to produce, given the outlook for prices." When oil prices rose in the 1970s, North Sea production became viable and production took place. Hobbs noted that this production did not disappear in the 1980s, after oil prices fell, because technology and innovation moved production costs lower. Today, the Canadian oil sands are often claimed to be too expensive to be viable in the long run. But Hobbs pointed out that production there did not shut down in the 1990s, when oil prices fell to $\$ 10$ per barrel.

Hobbs conceded that scientists may someday run up against some hard physical limits on the development of new energy sources. For example, the amount of energy required to turn poor-quality but still-available crude oil into a refinable product will probably raise energy costs. "That probably means that we won't be able to return to the kind of cost 


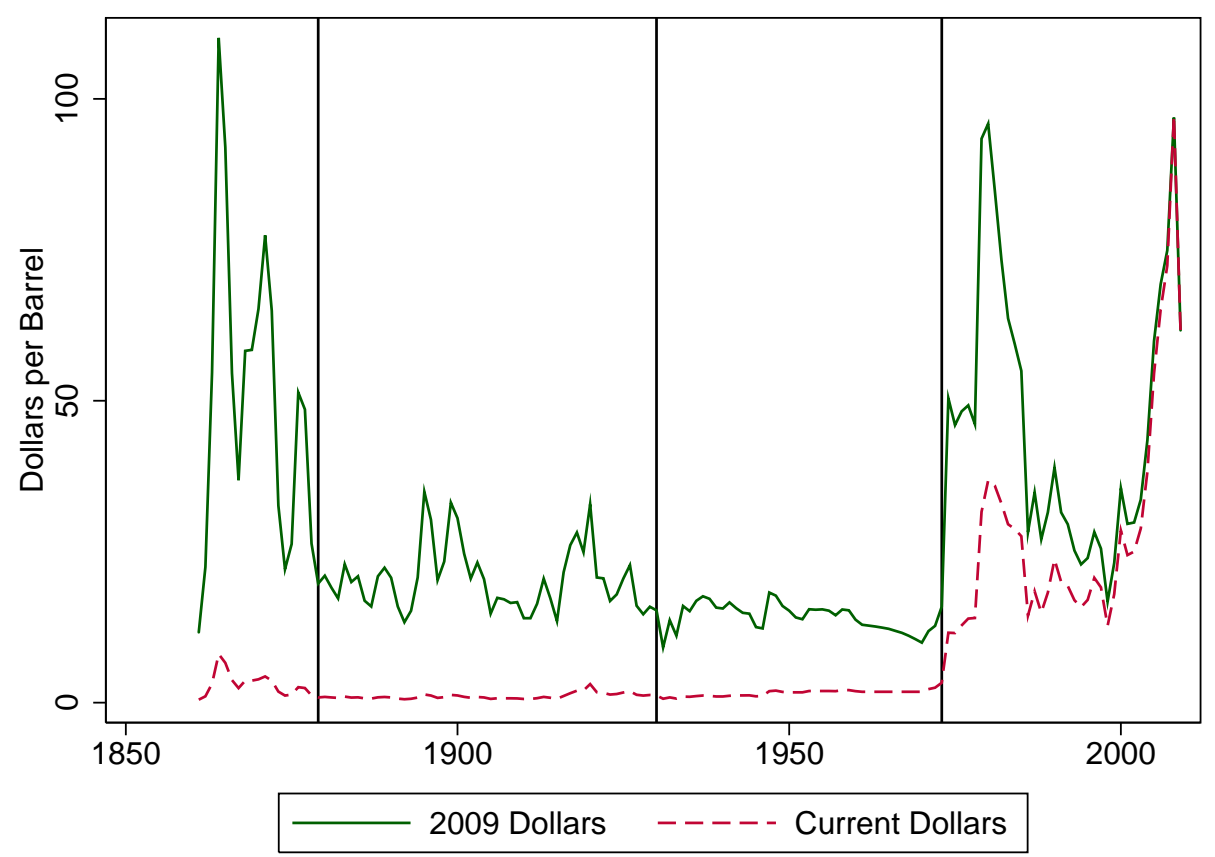

Figure 7. Price of Crude Oil, 1861-2009. Vertical lines correspond to the years 1869 (opening of first major pipeline, in Pennsylvania), 1930 (discovery of East Texas Oil Field), and 1973 (OPEC oil embargo). Data for 1861-1944 are U.S. average prices, data for 1945-1983 are Arabian light prices posted as Ras Tanura, and data for 1984-2009 are Brent dated prices. Source: BP, PLC. (2010).

structures that we had in the 1960s and 1970s," Hobbs said. "There will probably be some underlying shift in the cost of oil. But I guarantee you it's not to $\$ 100$ a barrel."

The discussant at this session, Eyal Dvir, expanded on Hobbs's remarks by providing a model for how uncertain oil demand from industrializing countries affects the oil market (Dvir and Rogoff 2009). The Dvir-Rogoff model posits that future world oil demand is highly uncertain when large countries are industrializing rapidly, because these countries are subject to frequent and long-lasting economic shocks. ${ }^{12}$ As noted in the introduction, in a world where supply is inflexible, the price effects of a demand shock depend crucially on the time horizon of the shock, with permanent shocks having much bigger effects on prices, even when oil inventories exist. A temporary shock to an emerging economy's growth rate serves as a permanent shock to the level of world oil demand, so these shocks would be expected to move oil prices a great deal.

Dvir and Rogoff contend that their model explains why the history of oil falls into three

\footnotetext{
${ }^{12}$ For example, consider a shock to China's economy that raises its annual GDP growth rate from a rapid 8 percent to a very rapid 12 percent. The Dvir-Rogoff setup assumes that China's growth rate falls back to 8 percent over ensuing years, which would leave the level of Chinese GDP permanently higher than it would have been without the shock. This type of permanent shock is to be distinguished from a temporary shock, in which the level of GDP eventually reverts back to its previous value, or to an ongoing linear trend.
} 
"epochs" since oil was first discovered in the early 1860s. ${ }^{13}$ During the first epoch (18611878), access to spare capacity was controlled by the railroad companies, who distributed most oil to its eventual users in the days before oil pipelines. In 1865, only three railroads served western Pennsylvania, where most oil was produced, ${ }^{14}$ and the oligopolistic structure of the railroad industry meant that the firms could charge high prices by limiting the provision of oil-transportation services. ${ }^{15}$ Thus, the initial $1861-1878$ epoch had the two requirements needed to generate volatile prices in the Dvir-Rogoff model. First, oil demand was uncertain because of economic shocks emanating from the industrializing United States. Second, access to spare capacity was limited by the anti-competitive structure of the railroad industry. As can be seen in Figure 7, which graphs the annual oil price from 1861 to 2009, this early epoch featured quite volatile oil prices.

Access to spare capacity was greatly enhanced by the development of the first longdistance oil pipeline in 1879 and by the discovery of the massive East Texas Oil Field in 1930. ${ }^{16}$ The development of the East Texas field created an oil glut that sent prices plummeting and prompted the U.S. government to issue production quotas to individual states (Dvir and Rogoff 2009, p. 15). By giving the U.S. government effective control over the supply of oil, and in particular by keeping production at the East Texas field much lower than full capacity, the quota system helped usher in a second, more stable period of oil prices. This stability continued even as the United States and other countries continued to industrialize, and even as two world wars and other assorted international crises buffeted the oil market. Any shocks to the oil market generated by uneven economic development, or by international tensions, could be offset by changes in U.S. production.

Dvir and Rogoff write that oil's second epoch drew to a close soon after the government allowed production at East Texas to reach 100 percent of capacity in 1971. In doing so, the U.S. government lost the ability to regulate access to spare capacity, which had smoothed prices for decades. It was not long before remaining sources of spare capacity in the Middle East began to exert their market power. Dvir and Rogoff date the third and current epoch of oil as beginning in 1972, the year before some members of OPEC initiated an oil embargo that more than doubled oil prices. In the current epoch, the industrializing countries that create uncertainty about future demand are located primarily in East Asia, with China as

\footnotetext{
${ }^{13}$ The history of the oil market since the mid-19th century is also discussed in Hamilton (2011).

${ }^{14}$ While most oil came from western Pennsylvania, it traded in a global market, as consumers and businesses around the world found oil products useful for lighting lamps and lubricating machinery.

${ }^{15}$ The railroad oligopoly encouraged the formation of Standard Oil. John D. Rockefeller's business plan was to create an oil concern large enough to bargain effectively with the railroads and obtain special "rebates" that competitors could not (Dvir and Rogoff 2009, p. 12).

${ }^{16}$ The first long-distance pipeline, the Tidewater, connected Pennsylvania's oil regions to Williamsport, PA, at which point the oil was transferred to railroad cars for transport to an oil refinery on the Delaware Bay.
} 
the canonical example.

As a general matter, the conference's first session stressed the importance of market structure and spare capacity in the historical determination of oil prices. Even though oil is a non-renewable resource, price gyrations have not stemmed from demand shocks running up against hard-and-fast limits on the amount of oil in the ground. Rather, prices have fluctuated since the early 1970s because demand or supply shocks have taken place in a market where ready access to spare capacity is limited, either by market structure (as stressed by Dvir) or by the legacy of past investment and technology cycles (as stressed by Hobbs). This way of thinking about supply is useful for analyzing the future as well as the past. As discussed in the next session, over the next several decades the limits to the supply of oil will probably not result from geological resource constraints. Rather, oil supply will be determined by the economic and political calculations of countries that can develop new oil sources easily.

\section{The Supply of Oil}

The presenter for the second session was Howard Gruenspecht, the deputy administrator of the EIA, who outlined the prognosis for oil supplies using both short-run and long-run models. In both cases, Gruenspecht began with a price forecast, and then explained the supply assumptions underpinning the projected price path.

Gruenspecht explained that as of June 2010, the EIA's short-term forecast for the oil market was close to the futures-market forecast at the time. This remained true of the nearterm forecast made in May 2011, as seen in Figure 8. In the EIA's short-term forecasts, the supply of oil produced by OPEC members is assumed to adjust to bring about the forecasted price, with non-OPEC production essentially determined as a residual. "Once productive capacity outside of OPEC is in place, production occurs, so long as it can earn a return after operating costs, royalties, and severance taxes," Gruenspecht said. "In other words, the non-OPEC operators generally behave as price takers in the world market." Some nonOPEC producers, including Norway, the United Kingdom, and Mexico, were expected to see declines in oil production in 2011, just as they had in 2009 and 2010, Gruenspecht said. But on the whole, Gruenspecht predicted that expanded production in countries like the United States, Brazil, Azerbaijan, and Kazakhstan would mean that overall non-OPEC production would rise somewhat in the next few years.

A recent innovation in the EIA's near-term forecast is the inclusion of confidence intervals around the price projection, which are also graphed in Figure 8. These intervals are based on observed prices of market-traded options in futures markets, Gruenspecht said, 


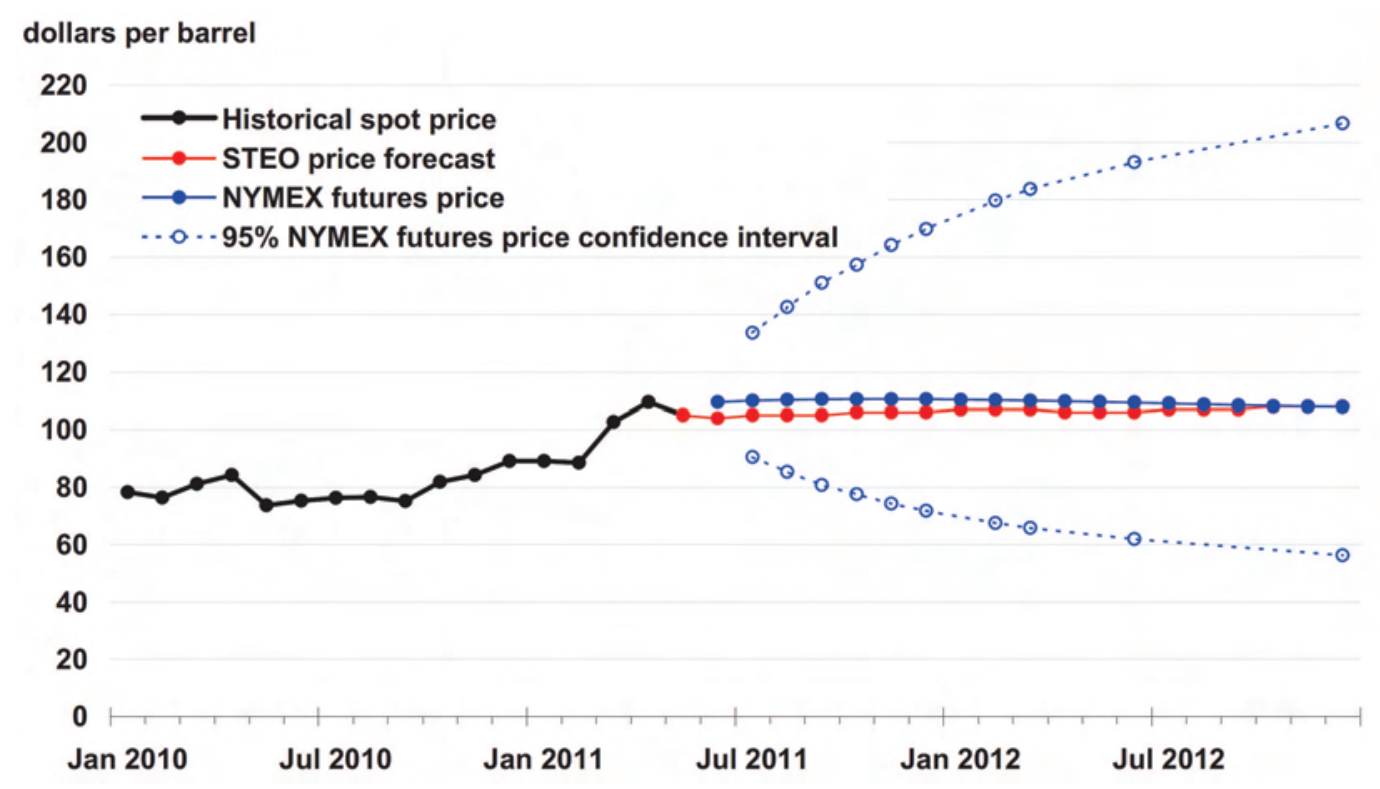

Figure 8. Oil Price Forecast of the Energy Information Administration, as of May 2011. Forecast corresponds to the price of a barrel of light, sweet crude in current dollars. Confidence intervals are derived from options-market information for the five trading days ending May 5, 2011. Intervals are not calculated for months with sparse trading in "near-the-money" options contracts. Source: Energy Information Administration, May 2011 Short-Term Energy Outlook.

adding that sources of near-term uncertainty arise from potential changes in world economic output, possible supply disruptions, and the interactions between the markets for oil and those for other commodities. The level of uncertainty implied from options prices is substantial, as confidence intervals for EIA's May 2011 forecast range from about $\$ 60$ to about $\$ 200$ per barrel only 18 months out. "Even short-run or short-term price forecasts are highly uncertain," Gruenspecht added, "something we continually stress to Congress, the administration, and the public."

For the long-term forecast, Gruenspecht discussed three potential scenarios for oil prices: the EIA's Reference, High-Price, and Low-Price paths. The key distinguishing feature of these paths, depicted in Figure 9, is OPEC's production strategy. The Reference case assumes that OPEC maintains its current 40-percent share of the global liquids market through 2035; if so, the EIA predicts that the price of oil will rise to around $\$ 125$ per barrel in 2009 dollars by 2035. The High-Price case assumes that OPEC reduces its target share of the global liquids market to 37 percent, which would help send the oil price to about $\$ 200$ per barrel over the same time period. ${ }^{17}$ In the Low-Price case, OPEC increases its production share to near 50 percent of the global liquids market, causing oil prices to tumble

\footnotetext{
${ }^{17}$ The High-Price case also assumes that the GDP growth rate for non-OECD countries is greater than that assumed in the Reference case. See Energy Information Administration (2011a, p. 61).
} 


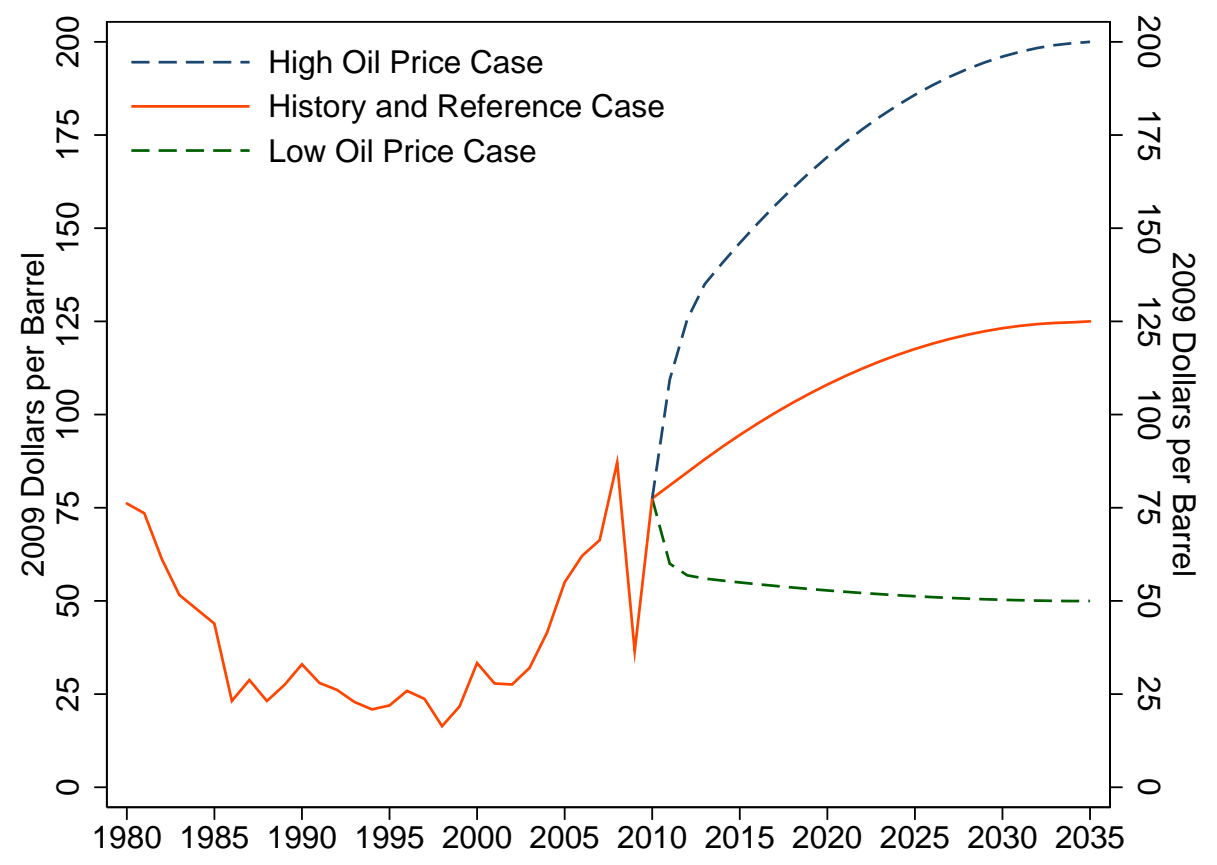

Figure 9. Three Long-Term Forecasts for Real Oil Prices from the Energy Information Administration. Forecasts correspond to the annual average price of light, low-sulphur crude oil in constant (2009) dollars per barrel. Source: Energy Information Administration, 2011 Annual Energy Outlook, Fig. 13.

to near $\$ 50$ per barrel in 2009 dollars.

Gruenspecht noted that over the long run, the contributions of unconventional sources of energy would grow from their currently low levels. Figure 10 shows that the supply of most unconventional sources, notably biofuels and bitumen, would grow more in the High-Price case than in either the Reference or Low-Price scenarios. But as a general matter, Gruenspecht's outlook for future technological advances in energy production was less optimistic than the one that Hobbs presented in the previous session. To start with, Gruenspecht noted that some sources of energy, such as biofuels, have limited compatibility with existing fueling infrastructure and vehicles, and are difficult to scale up appreciably. Second, technology and cost challenges have long plagued advanced biofuels or efforts to turn coal into liquid fuel (so-called "coal-to-liquid," or CTL technology). Third, both biofuels and technologies that turn natural gas into liquid fuels ("gas-to-liquid," or GTL) require a great deal of energy in the production process. Fourth, there is a long gestation period for projects like CTL, GTL, and efforts to further develop the Canadian oil sands. The high degree of uncertainty surrounding oil prices means a project might begin in a high-price environment, but eventually turn unprofitable if and when oil prices fall. This possibility limits the attractiveness of beginning the project in the first place. The bottom line, Gruenspecht said, 


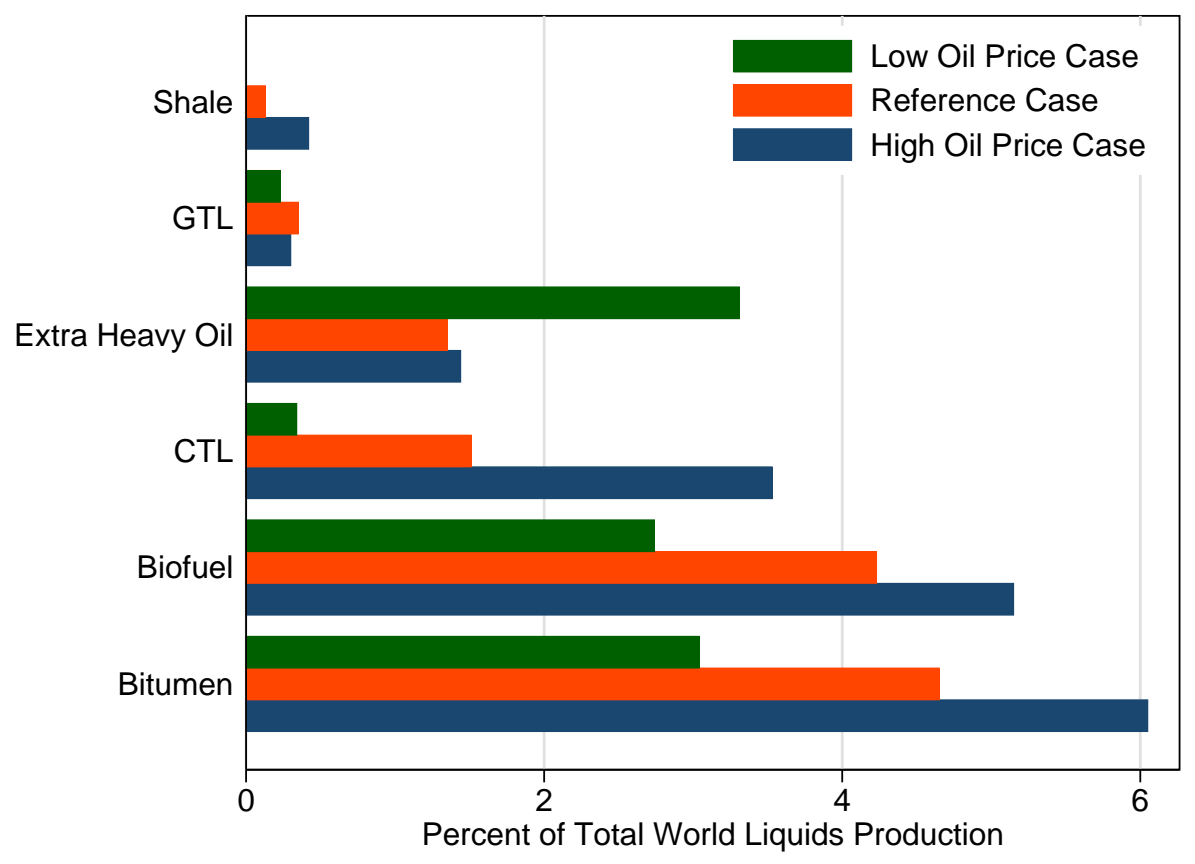

Figure 10. Production Forecasts for Liquid Fuel from Unconventional Sources Under Three Scenarios for Oil Prices. Source: Energy Information Administration, 2011 Annual Energy Outlook, Fig. 54.

is that conventional sources are likely to remain "dominant in the overall supply mix."

\begin{tabular}{lrr}
\hline & $1973-1985$ & $2003-2015$ \\
& Actual & IEO Ref Case \\
\hline World Liquids Demand & +2 & +9 \\
OECD & -4 & -2 \\
Non-OECD & +6 & +11 \\
Non-OPEC Conventional Supply & +13 & -1 \\
Unconventional Supply & $\approx 0$ & +4 \\
OPEC Conventional Production & -14 & +6 \\
\hline
\end{tabular}

Table 1. Adjustments in the Global Liquid-Fuels Market in Two Periods, in Millions of Barrels per Day. Forecasts in right-most column are for Reference Case long-term forecast from the Energy Information Administration's 2010 International Energy Outlook.

Another note of pessimism concerned the ability of oil-consuming nations to respond to the rising real price of oil in either the Reference or High-Price scenario. Gruenspecht explained that after the oil shocks of the 1970s, industrialized countries in North America and Europe responded to higher prices by becoming more efficient users of energy and by producing more oil themselves. As seen in Table 1, in the 12 years following the 1973 oil shock, oil demand among OECD nations fell by four million barrels per day (bpd) as consumers economized on fuel. At the same time, conventional production outside of OPEC rose by 
13 million bpd. In the 12 years following 2003, however, EIA projects in its Reference case that OECD oil demand will only fall by two million bpd, since the developed world has already adopted the easiest ways to reduce oil consumption, such as reducing the use of oil in electricity generation. Even more importantly, oil demand outside of the OECD (for example, in China) is expected to increase by 11 million bpd. On the supply side, production outside of OPEC is expected to decline from 2003 to 2015 by about 1 million bpd. The 2003-2015 projections "provide some insight into why we don't envision, in our Reference Case at least, a repeat of the sustained and sharp downward movement in real oil prices that occurred in 1986," Gruenspecht said.

In his conclusion, Gruenspecht stressed the ownership of spare capacity, which had featured so prominently in the previous session. "The key thing [for future oil supply] is really going to be what happens in OPEC countries, who hold the majority of the highquality resource," Gruenspecht said. "We think the availability of that high-quality resource acts to retard the investment in some of the high-cost options."

In his discussion of Gruenspecht's remarks, MIT's John Deutch stressed the political uncertainties that surround oil markets. Political machinations have long been part of the oil industry. But Deutch argued that in the past, geopolitical concerns centered on the damaging effects of temporary disruptions in oil supplies. This concern over acute supply shortage led to the development of the Strategic Petroleum Reserve, price-sharing agreements, and other measures to insulate richer countries from supply shocks.

As it happened, outright disruptions in oil supply have caused few problems in recent decades, Deutch said. He argued that the real problem today is the ability of oil producers to further their political agendas by exerting long-term pressure on large oil importers. "Oil is playing a large and continually growing role in our international diplomacy," Deutch said. "It influences and constrains the foreign policy choices that this country faces, and that we can exert with our allies on the world stage." As an example, Deutch claimed that Iran, which produces about three million barrels of oil per day, was engaged in supporting terrorism, developing a nuclear weapons program, and becoming involved in Iraqi politics. Deutch contended that Iran's oil has helped to shield it from world pressure in response to these policies.

A related feature of the current oil market is the importance of national, rather than investor-owned, oil companies. Referencing some data presented earlier in the session, Deutch noted that in his youth, about 80 percent of the world's oil resources were under the control of investors, with a small remainder under the control of national governments. Today, Deutch said, those percentages have almost exactly reversed. A consequence of this reversal is the emergence of opaque, state-to-state agreements between national oil compa- 
nies and oil-consuming countries, such as China's efforts to gain control of oil supplies in Africa. "The political and economic motivation for China's policy can be questioned-I certainly do so," Deutch said. "But there is no doubt that this is a move away from transparent markets."

Deutch urged conference participants to view the international oil and gas business as a geopolitical issue, not just an economic one, because international frictions in the oil market could someday escalate into open conflict. "We are going to go through a period of time when we still have tremendous tensions, geopolitical tensions, in oil and gas markets around the world," Deutch said. "They are almost inevitably going to lead to periods of conflict, perhaps even serious conflict. And those occasions when serious conflict occurs cannot be looked at only through an economic lens."

\section{The Demand for Oil}

The third session of the conference discussed the outlook for oil demand. Steven Fries, the chief economist for Royal Dutch Shell, framed his presentation by referencing three long-run challenges faced by the world oil market. The first challenge was foreshadowed by the central role of China and other developing economies in earlier sessions. Fries's presentation confirmed predictions of a surge in world energy demand due to rapid growth in emerging nations. Over the next 40 years, world GDP is expected to rise by 200 percent while population will rise from 6 billion to 9 billion, Fries said. Because much of this growth will take place in developing countries, it will have a profound effect on oil demand, given the nonlinear relationship between the per capita GDP of a country and the amount of energy it demands. As shown in Figure 11, energy demand is low for very poor countries, as their transport sectors in particular make little use of mechanized vehicles. As a country develops, energy demand begins to rise sharply at an annual per-capita income of around $\$ 10,000$. By the time that living standards reach U.S. levels, energy demand flattens out again.

Fries said that the world's second long-run energy challenge is finding ways to meet this rising demand. "This isn't a story about peak oil or lack of molecules in the ground," Fries said. "It's really about the capacity of the industry to expand at the rate that is implied by income and population growth on the demand side of the market."

The third energy challenge was environmental. Fries said that if supply were somehow able to match the oil demand implied by rising income and population levels, then carbon dioxide emissions would double by 2050, even though climate stabilization would require a halving of emissions over the same time period. 


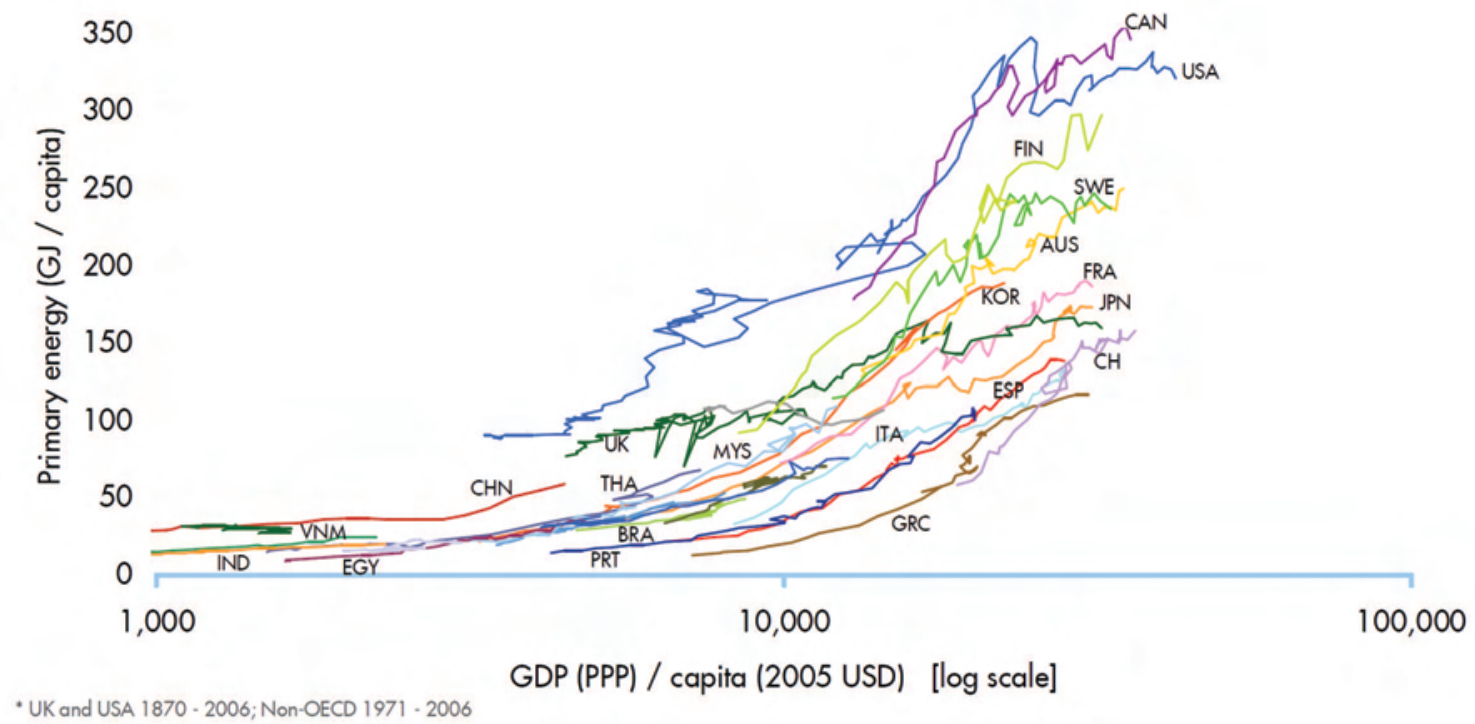

Figure 11. The Energy Ladder. Energy demand rises rapidly at levels of development now being reached by many developing countries. Source: Haigh (2008).

Fries then sketched out two broad scenarios for how the world might satisfy higher energy demand while responding to environmental concerns. In one scenario, which Fries labeled "Scramble," governments would focus on reacting to energy challenges rather than planning ways to address them. There would be few changes to current energy infrastructure; policy would try to maintain the status quo as long as possible, with energy issues framed as "energy security first and climate change second," he said. The end result would be a sequential approach. Energy policies would first make use of domestic energy sources more intensively, and then turn to addressing energy efficiency and climate-change concerns. A second scenario, called "Blueprints," would be a "more anticipatory and integrated approach," Fries said. This scenario would involve early and effective pricing on carbon dioxide emissions, as well as early shifts to electrification of the transportation sector and the development of alternative fuels such as hydrogen cells.

Figure 12 illustrates how these scenarios would affect energy use. Panel A portrays a benchmark "Business-as-Usual" scenario. In this case, energy demand in developing countries rises with GDP as it has in other countries in the past, after allowing for technological progress. The Business-as-Usual scenario also assumes that world energy supplies expand flexibly to meet this demand at a constant real price. Under these conditions, world energy demand for passenger-transport energy would be expected to more than double between 2010 and 2050, rising from about 60 to just under 140 exajoules per year, Fries said. ${ }^{18}$

\footnotetext{
${ }^{18}$ One BTU is equal to about 1,055 joules, and one exajoule equals $10^{18}$ joules. The exajoule is often used to measure energy demand on a world or national scale. Roughly speaking, a country that uses two
} 


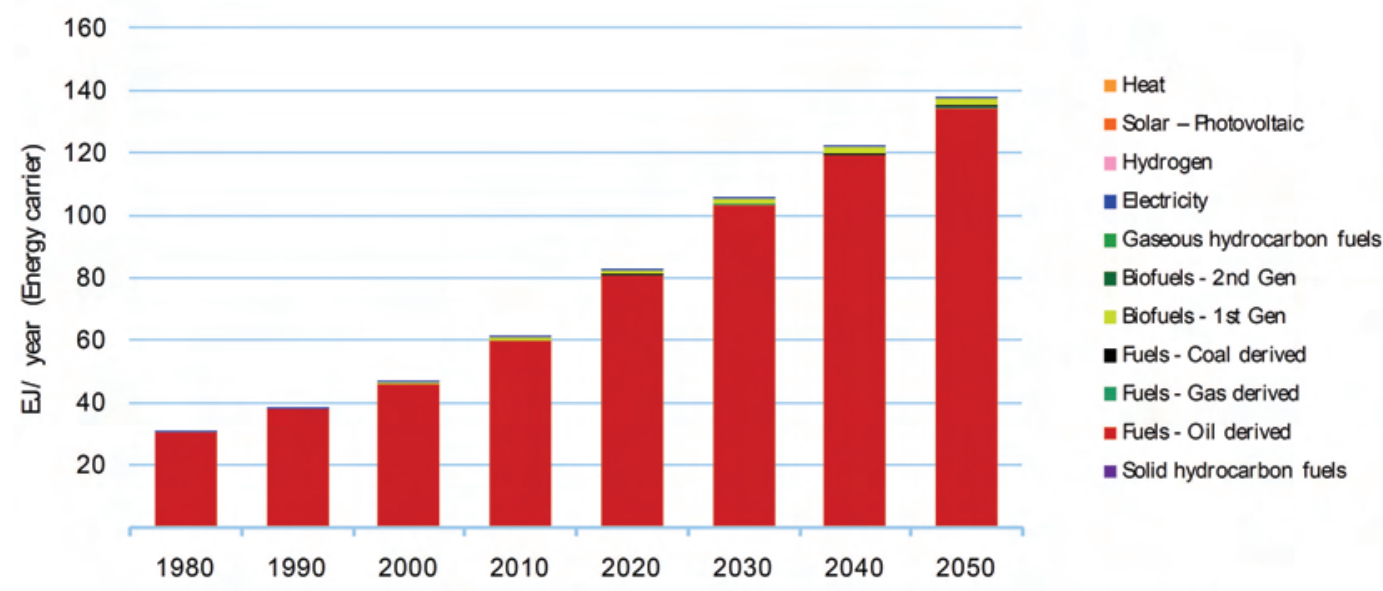

Panel A: Business-as-Usual Scenario

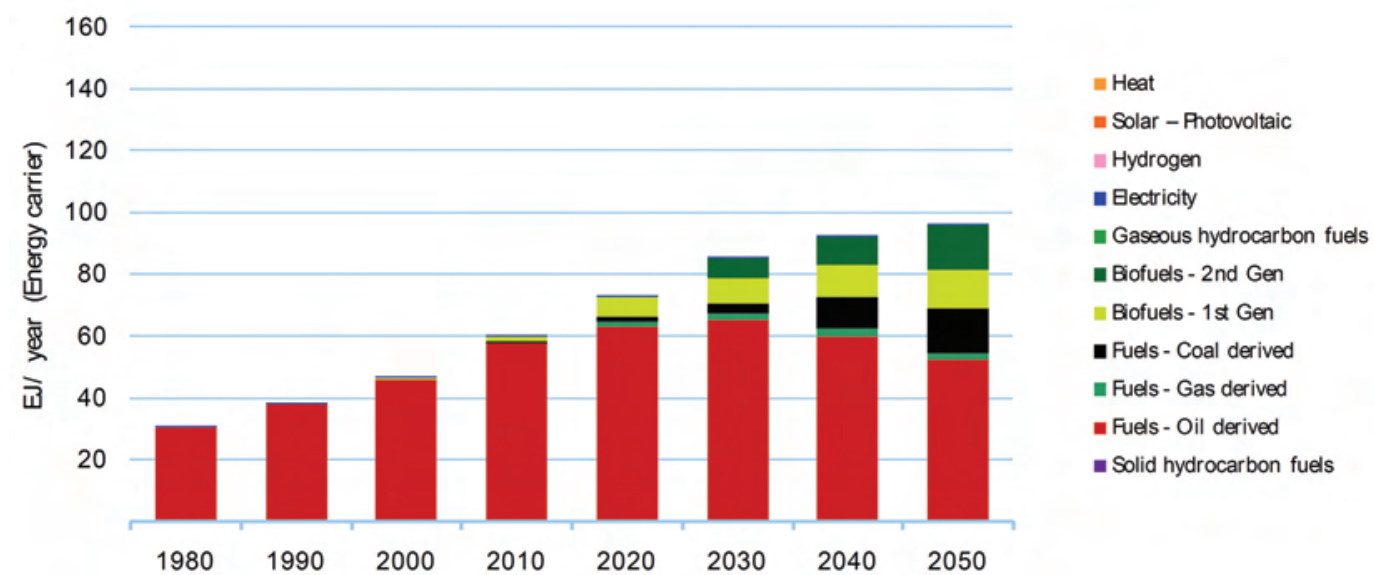

Panel B: Scramble Scenario

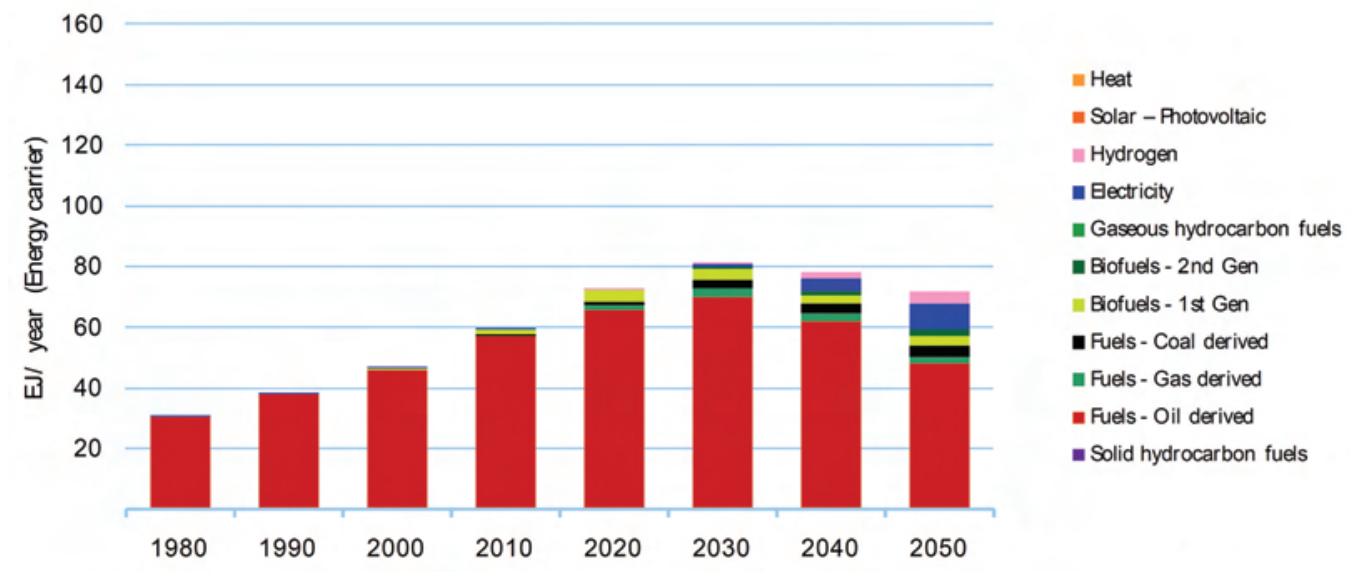

Panel C: Blueprints Scenario

Figure 12. Three Scenarios For World Energy Demand for Passenger Transport. The Business-as-Usual scenario assumes that the supply of oil expands to keep the real price of oil constant through 2050, despite a much greater demand for oil that is caused by world economic growth. The Scramble and Blueprints scenarios, constructed by Royal Dutch Shell and described in the text, are two potential responses to future energy challenges. 
Because the real price of oil remains constant in this benchmark scenario, there is no need to economize on the use of oil, so the Business-as-Usual scenario also implies that virtually all energy needs for passenger transport are met by using oil. The Scramble and Blueprints scenarios assume that energy supply is not perfectly elastic, so the total use of transport energy does not rise as much as in the Business-as-Usual scenario. Under the Scramble scenario, shown in Panel B, world transport energy demand rises to near 100 exajoules per year by 2050. The Scramble scenario also implies that oil alternatives, such as biofuels and fuels derived from coal and natural gas, would make up somewhat more than 40 exajoules of this demand. Under the more forward-looking Blueprints scenario, shown in Panel C, total transport-energy demand rises to only about 70 exajoules by 2050. Moreover, about seven exajoules of this demand would come from technologically advanced alternatives, including renewable electricity for battery electric vehicles, which emerge in the 2020s, and hydrogen fuel-cell vehicles, which arise a decade or so after that. In both the Scramble and Blueprints scenarios, however, oil-based fuels account for most of the world's energy for passenger transport over the next four decades.

The discussant for the session was Daniel Schrag, the Sturgis Hooper Professor of Geology at Harvard University and the director of the Harvard University Center for the Environment. Schrag commented extensively on the scientific challenges for some of the alternative technologies that appear in both the Scramble and Blueprint scenarios that Fries outlined. Regarding coal-to-liquids (CTL) programs, Schrag said that these technologies would probably be profitable at oil prices of $\$ 70-\$ 80$ per barrel. The main technology to produce liquid fuel from coal, called the Fischer-Tropsch process, was developed by German scientists in the early 20th century. Yet Schrag said that there has not been much CTL investment in recent years, as no plants have been built with Fischer-Tropsch technology since a South African plant was constructed in the early $1980 \mathrm{~s}^{19}$

As for gas-to-liquids (GTL), Schrag said that Shell was currently constructing a $\$ 19$ billion GTL plant in Qatar. This plant was expected to be profitable - in spite of high start-up costs - because Qatar is saddled with a lot of natural gas that is uneconomical to transport long distances to other countries. This allows Shell's GTL plant to purchase its natural gas input at low prices. ${ }^{20}$ Schrag also noted that the relationship between uncertain

exajoules of energy per year burns the equivalent of 1 million barrels of oil per day.

${ }^{19}$ Schrag noted that he is the carbon adviser to Rentech, Inc., a firm that produces certified synthetic fuels and electric power from carbon-containing materials. These materials include biomass, certain waste products, and fossil resources, such as coal.

${ }^{20}$ Since the conference took place in June 2010, oil prices have risen above $\$ 100$ a barrel, while U.S. natural gas prices have remained relatively low at about $\$ 4$ per million BTU. At this combination of prices, Schrag believes that a GTL plant built in the United States might make economic sense, although such a plant would be riskier than one built in an area with an abundance of stranded gas, like Qatar. 
oil prices and future investment was especially relevant for GTL projects. Though input prices for Shell's GTL plant are low, Schrag said, Shell executives should be concerned that a future drop in oil prices could make the GTL facility uneconomical. He said that these executives would be open to the use of offtake agreements, which would lock in sales to particular customers at pre-agreed prices. "The use of offtake agreements and long-term contracts, I suspect, will become a little more prevalent over the next couple of decades, as the scale of capital investment gets so large," Schrag said. ${ }^{21}$

Schrag then discussed the significant cost and environmental challenges of biofuels. He noted that some first-generation biofuels are now financially viable, citing the "tremendous potential" of sugarcane-based ethanol. Not only is this fuel economical at recent oil prices, Schrag said, but growing the sugarcane does not affect the environment much. "Essentially, sugar cane is a grass, in that you don't need to disturb the land much to cultivate it in a tropical environment," Schrag said. "So if the land-use impacts are not that great, then you can get significant scale and environmental benefits out of tropical sugarcane. And there is significant potential to increase capacity."

Schrag was less hopeful regarding other first-generation biofuels, such as biodiesel made from palm oil. A major concern is that palm oil production could hasten the deforestation of tropical countries. This is also true for feedstocks such as soybeans. He added that secondgeneration biofuels are "massively out of the money at the moment.... While a great deal of work is now underway to improve the economic viability of cellulosic ethanol, ${ }^{22}$ algae-based biodiesel, and other second-generation biofuels, scientists are at least a decade away from having a 'material capability' in those areas," he said. Schrag argued that the most likely source of diesel and jet fuel with a low or zero carbon footprint is synthetic fuels made with the Fischer-Tropsch process, using a combination of biomass and fossil fuels, such as coal or natural gas, along with carbon capture and storage to reduce the $\mathrm{CO} 2$ emissions from the synthetic process.

Schrag also agreed with Fries's predictions that battery electric vehicles would not significantly penetrate the U.S. car fleet until at least the 2020s, and that hydrogen fuel cells would lag behind even further. Schrag said that a daunting technological hurdle in developing electric cars is designing batteries that are powerful enough and cheap enough for everyday use. Even if scientists could build a battery capable of powering a car for short distances (such as daily commutes to work), and even if the resulting cars could fully saturate

\footnotetext{
${ }^{21}$ Schrag added that the adoption of another natural-gas technology, compressed natural gas (CNG), has only a modest effect on carbon emissions, though CNG does help reduce air pollution. Given the lack of appropriate fueling infrastructure, however, Schrag said that CNG makes economic sense only for vehicles that have central refueling points, such as city bus fleets or long-haul trucking companies.

${ }^{22}$ Cellulosic ethanol is produced from wood, grasses, corn husks, or other non-edible parts of plants.
} 
the U.S. auto fleet (a process that would probably take decades), the resulting reduction in U.S. oil use would be only about 25 percent, Schrag said. ${ }^{23}$ "Now that's a big number - one quarter," Schrag said. "But it doesn't solve the problem. It's not a panacea."

Schrag, who has done a great deal of academic research on climate change, agreed that a carbon tax or any regulatory regime that places a price on carbon would not affect oil very much. Because oil is an expensive source of carbon emissions, a price on carbon would raise oil-product prices very modestly relative to other fuels. "If we were rationally dealing with the climate problem and working on optimal solutions, the impact on oil over the next 20 or 30 years would be almost nil," Schrag said. "Because of its high price, or price per unit of carbon emissions, oil is the last place you want to start reducing emissions. But in the long run, eliminating carbon emissions from the transportation sector is essential if we are going to solve the climate problem." The question of whether future climate-change initiatives would in fact be efficiently designed was a topic addressed during the conference's luncheon remarks, described in the next session.

\section{Luncheon Remarks: The Future of Climate-Change Policy}

Robert Stavins, the Albert Pratt Professor of Business and Government at Harvard's Kennedy School of Government, delivered the conference's lunch talk. Stavins is also the director of the Harvard Project on International Climate Change Agreements, a group that aims to identify and advance science-based, economically rational, and politically feasible options for addressing climate change. ${ }^{24}$ Stavins began by noting that both the science and economics of the climate-change problem point to the need for a credible international approach. "And I emphasize the word "international'," Stavins said, "because this is a global commons problem. For any individual country, for any jurisdiction, the benefits of taking action will inevitably be less than the costs of taking action, even though globally the benefits exceed the costs. There is a very significant free-rider problem, so international cooperation of some kind ... will be required."

Though an international approach to climate change is necessary, Stavins did not give high marks to one of the most significant international agreements on the issue, the Kyoto Protocol. This agreement came into force in February 2005 with commitment periods for 2008-2012. The United States was the only industrialized country that did not participate

\footnotetext{
${ }^{23}$ Schrag arrived at the one-quarter figure by noting that about two-thirds of U.S. petroleum use is for transportation, as shown in Figure 3. The amount of oil destined for cars is about two-thirds of that amount, or about one-half of total petroleum use. Eliminating the use of oil for short-distance trips would cut this requirement in half, for a total reduction in petroleum use of one quarter.

${ }^{24}$ The group includes researchers from several fields of academia in various universities and countries, as well as representatives from private industry, non-governmental organizations, and governments.
} 
in the protocol, but Stavins said that U.S. non-participation made little difference. "The important thing is that even if the United States had ratified it and had participated, and even if all the countries of the world ... that participated did take action, the effects on climate change would be lost in the noise," Stavins said.

Stavins explained that a main problem with the Kyoto agreement was its dichotomous distinction between the developed and the developing world. In particular, the countryspecific Kyoto targets essentially exempted developing countries, even though these countries might be cost-effective places to reduce emissions. About 50 of these developing countries exempted from Kyoto now have higher per-capita GDP levels than the poorest countries that did participate, "so the distinction is out of whack," Stavins added. Moreover, the Kyoto commitments lasted only a limited number of years, so the agreement did not provide a long-term solution to the problem. "I frequently characterize the Kyoto Protocol as "too little, too fast'," Stavins said. "Other people, particularly our European friends, would say that the Kyoto Protocol was a good first step. But we can all agree that further steps are needed."

Going forward, Stavins said that appropriate climate change policy must acknowledge four facts. First, Stavins said that climate change is a stock-flow problem, using the classic bathtub analogy to make his point. "It's not the amount of water coming out of the faucet, it's the amount of water stuck in the bathtub, and we have a very slow drain," Stavins said. "The decay rate of greenhouse gases out of the atmosphere is decades to centuries long. So that requires a long-term view on this stock problem." Second, the stock-flow nature of the problem means that ambitious, short-term targets for emission reductions (like those in Kyoto) are not the most cost-effective way to solve the problem. The best approach is a "gradual ramp-up" in target severity that does not render large portions of the capital stock immediately obsolete, but instead steers future investment in the right direction. Third, likely increases in both population and economic growth mean that technological innovation must be part of the solution. For this to occur, the correct price signals are needed. Fourth, due to the international nature of the problem, durable climate-change policies should be international - but not necessarily global-in scope.

To Stavins, these four facts mean that addressing climate change is a marathon and not a sprint. "The right way to think about the international negotiations on climate change is as an ongoing process, much as we think about trade negotiations," Stavins said. "There are ups and downs, but it's not a single task with a clear-cut solution."

Stavins then turned to a discussion of the climate-change negotiations that took place in Copenhagen in December 2009. Many observers were disappointed after these meetings, because no sweeping, global, and binding agreements were produced. Stavins disagreed. 
"I would argue that it would have been actually unfortunate to have achieved what some would have defined as 'success' in Copenhagen - a signed international agreement, glowing press releases, and photo opportunities for heads of state," Stavins said. "And the reason I say that is because the only such agreement that was feasible would have been the Kyoto Protocol on steroids. That means more ambitious targets for what we used to think of as the industrialized world, and no responsibility whatsoever for other countries." The resulting agreement would not encompass several major emitters, Stavins said, because the U.S. would have rejected the agreement outright, and major developing countries like China and India would have been left out from the start.

The actual outcome, hammered out by the United States, Brazil, China, India and South Africa in the conference's waning hours, is a three-page document now known as the Copenhagen Accord. Stavins said this three-page document addresses two key failures of the Kyoto Protocol. First, the accord broadens the coalition of meaningful action to include all of the major emitting countries, not just the developed ones. By early June 2010, 130 of 194 countries around the world, accounting for 80 percent of greenhouse-gas production, had submitted their plans for real emission cuts, Stavins said. The accord includes a transparent framework for validating those cuts, as well financial help for the world's poorest countries as they adapt to a low-emission environment. A second way in which Copenhagen improves upon Kyoto is that Copenhagen expands the time frame for action, in recognition of the long-term nature of the problem.

Stavins conceded that the Copenhagen Accord is far from perfect. It does not place the world on track to achieve the ultimate goal of stabilizing the amount of greenhouse gases in the atmosphere at 450 parts per million CO2 equivalent, which would limit the amount of global warming to two degrees centigrade. Moreover, the distinction between developed and developing countries remains in principle, though it is blurred in action. ${ }^{25}$ Even so, Stavins said that the Copenhagen Accord frames the climate-change problem in the right way and encourages countries like the United States to construct their own appropriate polices.

What form should these policies take? A cost-effective emissions policy would equate the marginal costs of additional reductions in carbon emissions across all potential sources. Two policies that have this characteristic are cap-and-trade systems and carbon taxes. Because the marginal costs of reducing emissions in the transportation sector vastly exceed the marginal costs of abatement in the electricity sector, the oil-market impacts of a costeffective emissions policy would be limited. ${ }^{26}$ To show this, Stavins then presented some

\footnotetext{
${ }^{25}$ In particular, the Copenhagen Accord has one paragraph stipulating the responsibilities of developed, or "Annex I" countries, followed by another paragraph with the responsibilities of developing, or "non-Annex I" countries. But Stavins pointed out that the two paragraphs say essentially the same thing.

${ }^{26}$ The carbon intensity of petroleum and coal are similar, but a great deal of inefficiency in the trans-
} 


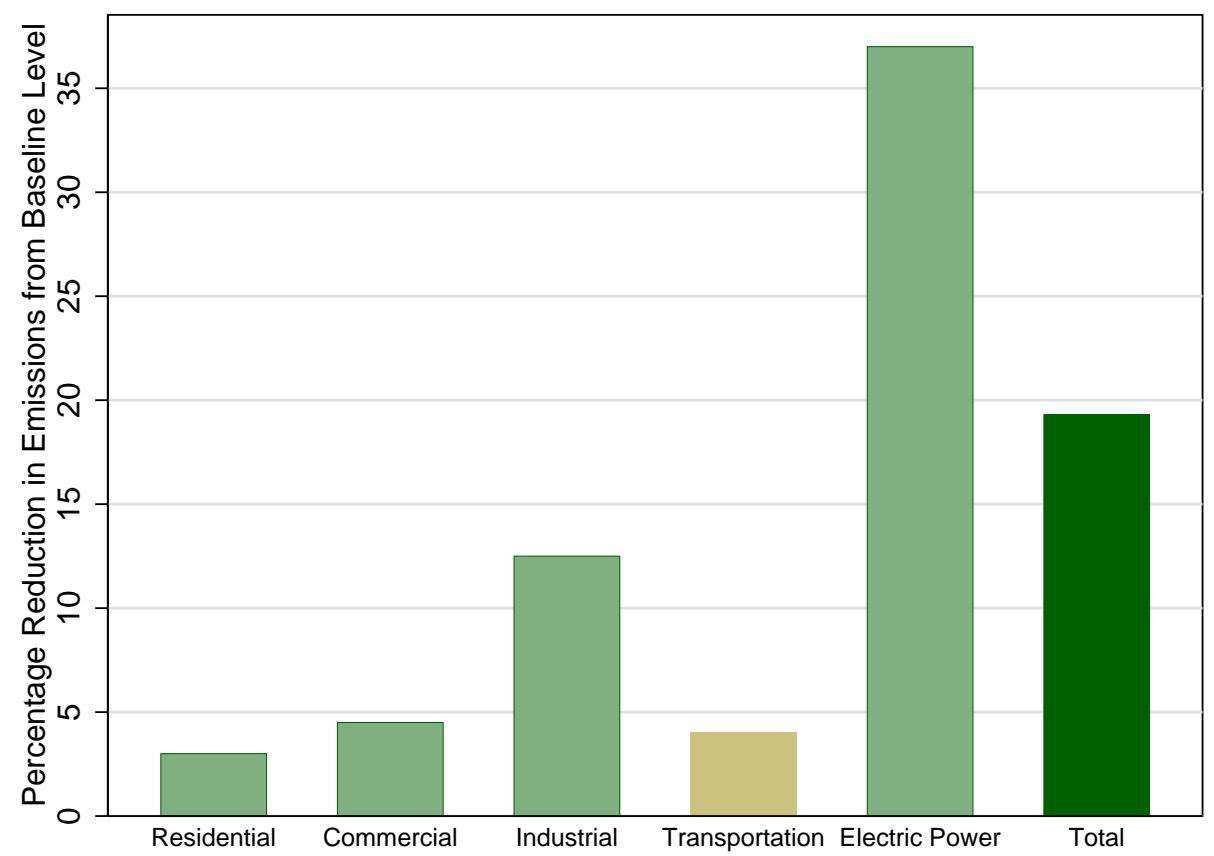

Figure 13. Reductions in C02 Emissions Under an Efficient Cap-and-Trade System. The figure shows the percentage reduction in sectoral C02 emissions in 2030, relative to baseline, assuming an economy-wide emissions cap that yields a $\$ 35$ per ton allowance price in 2030. Estimates presented by Robert Stavins based on analysis by the Energy Information Administration.

cost estimates for the year 2030 for a climate-change policy that gradually reduced U.S. emissions by 83 percent by 2050. The cumulative cost of the program would be $0.3-0.9$ percent of GDP, Stavins said. ${ }^{27}$ The emissions policy would cause coal prices to rise by 250-300 percent by 2030, prompting a great deal of substitution away from coal in the generation of electric power. ${ }^{28}$ Gasoline prices would rise by only about 9 percent by 2030 , relative to a business-as-usual benchmark, while gasoline demand would decline by about 5 percent and oil imports would decline by about 9 percent. All in all, as shown in Figure 13, the electric-power sector would account for the lion's share of emissions reductions from a cost-effective policy. The impact on the transportation sector would be much smaller

If Congress were to enact an overall emissions policy, it would probably not be the costeffective kind suggested by economic analysis, Stavins said. Rather, the policy would be

portation sector has already been squeezed out of this system by mileage standards for vehicles. As a result, further emissions reductions in the petroleum-intensive transportation sector are more expensive than reductions in the coal-intensive electricity sector.

${ }^{27}$ In keeping with the positive, rather than normative, tenor of his analysis, Stavins left it to his audience to characterize this cost as either "trivial, small, significant, or devastating."

${ }^{28}$ At first, coal would give way to natural gas in power generation, with nuclear power and renewable sources of energy potentially taking a greater importance in later years. Stavins said that the increased use of nuclear power in electricity generation could be justified on economic grounds under a cost-effective emissions system, but it might still face stiff political opposition. 
some form of cap-and-trade policy combined with more politically palatable additionswhat Stavins termed "cap-and-trade plus/minus." While cap-and-trade policies and carbon taxes are much beloved by economists, they are less popular with Congress and the public, who instead prefer more opaque and more costly policies like increases in Corporate Average Fuel Economy (CAFE) standards, Stavins said. "Remember, what Congress is sensitive to is not how costly a particular approach is, but how visible the costs are of that particular approach," Stavins said. "And cost-effective approaches, like carbon taxes and cap-andtrade systems, make costs transparent to the political process. CAFE standards, which are vastly more costly than what a proportionate gasoline tax would be needed to accomplish the same thing, are 'free' as far as anyone can tell at first blush, without analysis."

Another reason that a pure cap-and-trade or carbon tax might not pass Congress is that its small effect on the transportation sector might be taken as a weakness of the program. Stavins said that when environmental activists in Washington are told that a cap-and-trade system or carbon taxes would have little effect on the transportation sector, they often argue for additional policies that will affect transportation more significantly. "And those arguments, in the wake of the Gulf oil spill and the increased hostility towards oil imports and oil production, are going to have profound effects," Stavins said.

Stavins concluded by noting that even if Congress fails to pass a comprehensive climate bill, climate policy will still move forward. For example, in 2011, the Environmental Protection Agency will take a more aggressive role in regulating carbon dioxide and other greenhouse gases, thanks to a recent Supreme Court ruling that permits the EPA to determine that these gases endanger the public's health. The EPA's subsequent endangerment finding requires the agency to issue regulations for these gases under the Clean Air Act. These regulations are not well suited to address climate change, Stavins said, but they could encourage Congress to devise a more comprehensive and cost-effective policy. In addition, a number of sub-national policies are likely to come on line. California recently enacted the Global Warming Solutions Act, which provides for CO2 reductions that are more stringent than those in any proposed federal legislation. ${ }^{29}$ Additionally, the Regional Greenhouse Gas Initiative has instituted a cap-and-trade system among electricity generators in the Northeast, with the goal of reducing CO2 emissions from the power sector by 10 percent by 2018. ${ }^{30}$ "The good news is that these systems can be linked, just as you can link international systems," Stavins said. "It will be grossly inferior, however, to a national approach."

\footnotetext{
${ }^{29}$ Specifically, the act calls for California's carbon emissions to fall to 1990 levels by the year 2020, which is a 25 percent reduction. See http://www.arb.ca.gov/cc/ab32/ab32.htm for details.

${ }^{30}$ More information on the Regional Greenhouse Gas Initiative is available at http://www.rggi.org/home.
} 


\section{Financial Innovation and Oil Markets}

When CFTC Commissioner Bart Chilton addressed the question of how financial innovation may have affected the price of oil and other commodities, the "flash crash" of May 6, 2010, was clearly at the forefront of his mind - naturally enough, since the CFTC had been charged by Congress with finding out what had happened and drawing lessons for the regulatory reform proposals under consideration at that time. During this tempestuous episode, the major indexes for U.S.-based equity futures and securities plummeted 5-6 percent in a matter of minutes, then largely recovered almost as fast. Nevertheless, during this brief period, 20,000 trades involving 300 securities were executed at 60 percent or more away from their pre-crash prices. These trades were then canceled after the markets had closed under rules covering "clearly erroneous" trades.

Against this background, the Commissioner began by pointing out that 80 percent of trading on the regulated U.S. futures exchanges is now electronic, and that algorithmic and flash trading ("nanosecond arbitrage") are now commonplace. He hypothesized that the size and speed of this so-called "fintech" trading had contributed to the events of the flash crash, suggesting the potential need for limits on the size and speed of trades and for mandatory circuit breakers applied consistently across all markets and contracts. ${ }^{31}$

The Commissioner also expressed concern regarding the rapid growth of the futures markets and the increasingly important role of "massive passive" investors like the commodity index traders. ${ }^{32}$ Referring to the predicaments raised in the movie, "Big," 33 the Commissioner warned that while trading on the regulated futures exchanges now amounts to roughly $\$ 5$ trillion annually, this volume is entirely dwarfed by unregulated and less trans-

\footnotetext{
${ }^{31}$ At that time the Commissioner did not know, as the report of the staffs of the CFTC and SEC later revealed, that at 2:32 p.m. on May 6, 2010, a large mutual fund group had initiated a program to sell 75,000 E-Mini contracts, valued at $\$ 4.1$ billion. Although alternative (slower) methods of executing this trade were available, the trader chose to execute its sell program via a sell algorithm that was programmed to feed orders into the June 2010 E-Mini market at an execution rate set to 9 percent of trading volume over the previous minute - without regard to price or time. In the event, the sell program was executed in 20 minutes. Moreover, as buy-side liquidity evaporated, the E-Mini dropped almost 2 percent in 15 seconds as it approached its intraday low. Finally, at 2:45:28 p.m. the CME Stop Logic Functionality triggered a brief 5-second pause in E-Mini trading. When trading resumed, the E-Mini began to recover. Nevertheless, the liquidity crisis in the equity markets continued, as automated trading systems used by many individual liquidity providers called for a temporary pause, causing many market makers to offer less liquidity or withdraw entirely. See U.S. Commodity Futures Trading Commission and U.S. Securities and Exchange Commission (2010) for details.

${ }^{32}$ Seeking to diversify the risk of traditional portfolios of stocks and bonds, commodity index traders take long, passive, fully collateralized positions in investment funds that track commodity indexes such as the Standard and Poor's/Goldman Sachs Commodity Index (GSCI) and the Dow Jones-UBS Commodity Index (DJ-UBS).

${ }^{33}$ In this film the central character, a young boy, gets his wish to be "big" but does not have the experience or sophistication to handle the situations that his adult body encounters.
} 
parent over-the-counter (OTC) trading of about $\$ 600$ trillion a year - a number that is "big any way you slice it," Chilton said. He also pointed out that it was in this OTC market that the AIG got into trouble building huge positions in credit default swaps. The Commissioner went on to argue that much of the growth and volatility in the U.S. futures markets that accompanied the recent run-up in energy prices was driven by investments by the massive passives with their "untraditional" but predictable long-only, price-indifferent trading strategy. In support of his concerns, he cited recent work by Tang and Xiong (2010), which finds that commodity-index trading has created a link between commodity and financial asset prices and increased commodity-price volatility - as discussed further below.

Commissioner Chilton readily acknowledged that speculators like the massive passives add to the depth and liquidity of the futures markets, thereby strengthening characteristics that are essential to the price-discovery process. "We want people with market information to be bringing that into the pits, to be trading on it, to be using it for price discovery," Chilton said. But he also argued that from time to time the CFTC has seen trading practices that didn't rise to the legal definition of "manipulation," but that still had negative and uneconomic impacts on commodity prices. Accordingly, while he was pleased that financial regulatory reform was, in his view, headed in the right direction, he also saw the need for three critical additions to the legislation under discussion.

In particular, Chilton called for 1) establishing position limits across markets; 2) increased authority for the CFTC to prosecute disruptive trading practices in regulated futures markets; and, most importantly, 3) the extension of regulatory oversight to the "dark" OTC markets by requiring that OTC trades be executed and cleared on regulated exchanges. ${ }^{34} \mathrm{He}$ pointed out that we have had position limits in the futures market for agricultural commodities for years. Why not for energy and metals as well? He also said that because the CFTC has historically had much difficulty proving "manipulation," the CFTC needs authority similar to that given to the SEC, in order to prosecute manipulation more effectively.

James Overdahl's remarks complemented Commissioner Chilton's presentation by providing additional background information and by offering an alternative - and considerably more skeptical - view than the Commissioner's regarding the desirability of additional controls on the derivatives markets. While Overdahl acknowledged that, at $\$ 600$ trillion, the OTC market is indeed big, he also reminded the participants that growth in this notional value reflects price gains as well as double counting. He also pointed out that there are

\footnotetext{
${ }^{34}$ The Dodd-Frank Wall Street Reform and Consumer Protection Act, signed into law after the conference took place, directs the CFTC to establish limits on trading or positions held by any group or class of traders in futures contracts and commodities traded on a designated contract market. It also grants the CFTC exclusive enforcement over swap markets, and requires that a swap be submitted for clearing by a registered clearing organization if the clearing organization will accept it and the CFTC determines that it must be cleared.
} 
sound economic reasons why investors want the exposure that commodity-linked investments provide. Citing Gorton and Rouwenhorst (2006), Overdahl explained that investors want exposure to commodity-based assets because returns on commodity futures are negatively correlated with those on equities and bonds. Consequently, commodity index funds provide an efficient way of diversifying a traditional portfolio of stocks and bonds as well as a hedge against inflation. As mentioned above, these investors generally follow a very deliberate, long-term asset allocation strategy, such as passively tracking a commodity index and rolling their positions, regardless of price and well before they mature, into the next nearest contract. Investors gain direct exposure to commodity-based assets in the regulated futures market or indirect exposure through swap dealers operating in the OTC market; the swap dealers, in turn, hedge any unwanted exposure in the futures market. Thus, either way, the CFTC can see (most) of these transactions. Accordingly, Overdahl asserted, the CFTC is not "flying blind" and also has the authority to ask large traders about their cash or OTC positions whenever it has concerns.

As for the price impact of these long positions, Overdahl argued that while a sustained increase in demand for commodity-based products could affect prices permanently if it were viewed as coming from "informed" investors, the index traders are generally perceived to be "uninformed" and thus attract speculators, who take offsetting positions and wipe out any permanent price effect. In support, he cited his work with several co-authors (Buyuksahin et al. 2008), which shows that prices of commodity futures contracts, which once priced as if traded in segmented markets, have grown increasingly tightly correlated across maturities since 2004 when financial investment in these markets began to surge. ${ }^{35}$ The result has been deeper, better informed markets that allow cheaper and more effective hedging.

Overdahl also mentioned recent research by Stoll and Whaley (2009) that sets out to evaluate whether commodity index trading is a disruptive force in the wheat futures market in particular or in the commodity futures market more generally. These researchers find that futures prices for commodities in a given sector (such as grains or metals) move in similar ways whether they are included in or excluded from commodity futures trading programs. This pattern suggests that fundamentals determine these correlations - not the activity of index traders. Stoll and Whaley (2009) also find evidence that the huge and predictable volume of rolls has a positive but insignificant effect on prices of most commodities; the authors interpret this result as evidence of the depth and absorptive capacity of the futures markets. However, Stoll and Whaley also find that in the oil futures market, the return

\footnotetext{
${ }^{35}$ Buyuksahin et al. (2008) find that real and financial sector fundamentals and the futures market activities of certain categories of traders help to explain increased cointegration of futures prices across maturities. In particular, cointegration rises with the market activities of financial traders in one- and two-year contracts and of commodity swap dealers in near-term contracts.
} 
differential associated with the roll is both positive and significant. Moreover, price changes in the oil-futures market vary positively and significantly with the notional value of the roll; the authors find no such relationship for the other commodities studied. Finally, Stoll and Whaley also look for evidence that commodity index flows Granger cause commodity price changes (controlling only for lagged futures returns). They found no such evidence for commodity index traders. However, they do find that net flows from other non-commercial traders classified as "speculators" do have a significant positive impact on prices for all 12 (non-oil) commodities examined.

In addition to Stoll and Whaley's mixed evidence on the effect of speculation on commodity prices, Tang and Xiong (2010) argue that since the growth of commodity-index investment in the early 2000s, commodity futures prices have become increasingly correlated with each other and with the prices of financial assets. This development has been particularly pronounced in the case of commodities included in the popular GSCI and DJUBS commodity indexes. Before the early 2000s, commodity prices did not move in sync with each other or with equity prices. But during the collapse of the stock market in 2000, analysts discovered a small negative correlation between returns on commodities and stocks, and investment banks began to promote commodities as a new asset class for prudent investors. Although Tang and Xiong found evidence that demand from emerging markets (particularly China) does help to explain the boom-bust behavior of some U.S. commodity prices in recent years, they also show that commodity prices in China did not become significantly more correlated with one another after 2004, thereby undermining the argument that demand from emerging Asian economies largely explains the increased co-movement of commodity prices in the United States. Instead, the authors find that the financialization of commodities has altered the determinants of commodity prices to include a set of financial factors - like changes in the risk appetite for stocks, bonds, and the U.S. dollar or the need for portfolio rebalancing - in addition to traditional demand and supply fundamentals. As a result, Tang and Xiong conclude, today's commodity prices exhibit increased co-movement and increased volatility.

Nevertheless, there is still little consensus on whether research to date has definitively established a strong role for speculation in recent commodity-price movements. Given the paucity of evidence that financial traders have had a lasting effect on commodities prices, Overdahl concluded by asking why we need position or concentration limits in derivatives markets, as Commissioner Chilton and the CFTC have proposed. Historically, the justification for position limits has been to protect the clearing house or to eliminate manipulation. But Overdahl noted that position limits appear to be attractive today to those who believe that such limits will reduce volatility or even influence the price level. Moreover, position 
limits on individual markets might impede their competitive position and growth. Rather than limiting market size, Overdahl would prefer to leave markets open so that investors who believe that a price is wrong can enter, thereby improving price discovery and reducing concentration.

To sum up the discussion of the financialization of commodity markets, participants in the session generally agreed that the growing use of oil and other commodities as financial assets has increased the depth, liquidity, and cointegration of the related derivatives markets and that the resulting improvement in the price discovery process has benefitted all market participants. On the other hand, financialization has also brought new, non-traditional investors with non-traditional goals into the commodity markets, thereby changing the determinants of oil prices, say, from the supply and demand for oil as an input to production to the supply and demand for oil as an input to production and as an instrument for managing portfolio risk and hedging against inflation or the U.S. dollar. The effects of this change remain subject to debate.

\section{$7 \quad$ Modeling Oil Prices}

A large econometric literature investigates the best way to model oil prices. The goal of this research is to determine whether any particular movement in oil prices results from a change in supply, a change in demand, or a shift in future expectations that prompts a change in speculative oil trading. One oil-price movement that is an obvious candidate for study is the 2003-2008 run-up in oil prices that was referenced throughout the conference. As noted above, some participants blamed this increase on an expansion of world economic activity, while others pointed to financial speculation in oil markets.

In his presentation, Lutz Kilian of the University of Michigan discussed a new econometric strategy to identify oil-market shocks. Kilian's presentation was based on a recent paper (Kilian and Murphy 2010), co-written with Daniel Murphy, that blends two strands of the oil-pricing literature. One strand interprets the oil price as an asset price. Under this approach, shifts in the expectations of forward-looking traders cause both oil prices and the desired level of oil inventories to change. A second strand of the literature models the oil price as a flow equilibrium outcome. At any time, there is a per-period flow demand for oil set against a per-period flow supply from oil producers. The flow equilibrium price is where these flow supplies and demands are equal.

One of the major difficulties in conducting econometric work on oil prices is that the expectations of oil traders are hard to observe. In particular, existing studies have had to assume that expectations are backward-looking, dependent only on past data. In reality, of 
course, expectations are likely to be forward-looking, so researchers will be unable to proxy for expectations with past data alone. In order to incorporate expectations into their model, Kilian and Murphy use an indirect approach. An increase in speculative demand for oil should show up as an increase in the demand for oil inventories. ${ }^{36}$ By including oil-inventory data in their model, Kilian and Murphy are able to measure the effects of expectational shifts without having to obtain direct information on the expectations themselves. ${ }^{37}$

The data requirements for the Kilian-Murphy method include four series: the change in world crude oil production, an index of global economic activity, the real price of oil, and the change in above-ground global oil inventories. These four series are assumed to be driven by four fundamental, or "structural," shocks. The first structural shock is a classic flowsupply shock, of the type that often accompanies political unrest in oil-producing regions. The second shock is a flow-demand shock that would accompany an unexpected increase in global economic activity. The third shock is a shock to the demand for above-ground inventories arising from expectations. As noted above, anything that affects views on the future supply or demand for oil would be a candidate for this third type of innovation, including fears of a war in the Middle East, expectations that world economic activity would soon increase, or a prediction that a new energy-saving technology is about to hit the market. Each of these expectational changes should affect oil prices in the future, which would in turn affect the profitability of holding oil inventories today. Finally, a fourth shock captures all price determinants that are not captured by the three previous shocks.

\begin{tabular}{lccc}
\hline & $\begin{array}{c}\text { Flow } \\
\text { Supply } \\
\text { Shock }\end{array}$ & $\begin{array}{c}\text { Flow } \\
\text { Demand } \\
\text { Shock }\end{array}$ & $\begin{array}{c}\text { Speculative } \\
\text { Demand } \\
\text { Shock }\end{array}$ \\
\hline Oil Production & - & + & + \\
Real Economic Activity & - & + & - \\
Real Oil Price & + & + & + \\
Inventories & & & + \\
\hline
\end{tabular}

Table 2. Identifying Assumptions on the Sign of Impact Responses in the Kilian and Murphy (2010) Model. All sign restrictions involve weak inequalities.

To identify the econometric model, Kilian and Murphy require some way of mapping these four structural shocks into the four observed data series. They achieve identification

\footnotetext{
${ }^{36}$ For example, if traders expect a decrease in future oil supply, or an increase in future oil demand, then traders will also expect an increase in the future price of oil. This future price increase, in turn, will raise the attractiveness of holding oil inventories today, because the inventories are likely to become more valuable over time.

${ }^{37}$ Note that this identification strategy rests on two assumptions that may not always pertain. First, it assumes that above-ground storage capacity is unconstrained. Second, it assumes that OPEC's demand for below-ground inventory does not shift.
} 
by imposing "sign restrictions," which are based on a priori knowledge of how the structural shocks would affect the observed data. These identifying assumptions are shown in Table 2. As shown in the first column, an adverse flow supply shock should reduce both oil production and global economic activity, while raising the real oil price. Hence, the first two rows of the first column have minus signs and the third row has a plus sign. In the second column, a positive flow demand shock should raise oil production, real activity, and oil prices. Finally, a speculative demand shock raises production, prices and inventories while reducing economic activity. These restrictions are accompanied by some additional identifying assumptions, such as bounds on short-run elasticities of oil demand and oil supply. Kilian and Murphy use a computer algorithm to sift through five million potential mappings between structural shocks and data series. By construction, each of these mappings is able to explain the observed movements in the four series using movements in the four structural shocks. But only 14 mappings explain the data in ways that are consistent with both the sign restrictions on the structural shocks in Table 2 and some additional restrictions needed to make the estimation method more precise. Thus, Kilian and Murphy's procedure leaves them with 14 statistical models that are potential representations of the truth. ${ }^{38}$

Kilian reported that each of the 14 acceptable models tells a similar story about the importance of demand, supply, and speculative shocks in recent oil-price movements. Results from a benchmark model are reported in Figure 14, which shows the cumulative effect of the three main structural shocks on the real price of oil. ${ }^{39}$ The middle panel of this figure shows that increases in the flow demand shock, arising most probably from an increase in global economic activity, explain most of the 2003-2008 increase in the price of oil. Kilian noted that world GDP forecasts consistently underestimated economic activity during this time, providing further evidence that flow demand shocks were positive in this period. Higher flow

\footnotetext{
${ }^{38}$ Formally, the Kilian and Murphy (2010) method estimates a reduced-form vector autoregression (VAR) of the four data series using two-year lags of monthly data from Feburary 1973 through August 2009. Five million rotation matrixes for the reduced-form VAR are then drawn and implied impulse response functions for each rotation are calculated. Rotations are discarded if the implied impulse responses do not satisfy the a priori sign restrictions. In practice, the sign restrictions are generally not sufficient to precisely identify an oil-price VAR model, a point made in Kilian and Murphy (2009). Thus, some additional restrictions beyond the sign restrictions are used. Two additional restrictions involve the supply and demand elasticities implied by the candidate models. In the baseline parameterizations, the oil-supply elasticity of a retained model must be below 0.025 and the implied oil-demand elasticity must be between -0.8 and zero. Finally, a set of dynamic sign restrictions rules out the possibility that unanticipated oil disruptions cause a strong decline in the real price of oil below its starting level, a circumstance that would would run counter to the standard view of an adverse supply shock. There are no dynamic sign restrictions on the responses of the four series to either flow demand shocks or to speculative demand shocks. All told, 14 out of the five million potential models satisfy all restrictions.

${ }^{39}$ The benchmark model was chosen out of the 14-member admissible set of models, because the impact oil-price elasticity of oil demand it implies is closest to the median of this variable among all admissible models. But Kilian said that the qualitative results regarding the importance of the three types of shocks to the four data series were similar across all 14 models.
} 
demand is also responsible for price increases in the late 1970s and early 1980s, according to the model.

The speculative shock, whose effects are shown in the bottom panel of Figure 14, affects oil prices in some years, including 1978, 1986, and 1990. In particular, Kilian said that in 1990, concern that Saddam Hussein would invade Saudi Arabia after taking over Kuwait drove a sharp increase in the speculative demand for oil inventories. ${ }^{40}$ Yet movements in the speculative shock play virtually no role in the mid-2000s. Moreover, the model gives little or no support to the idea that supply cuts from OPEC were behind the mid-2000s price increase. These cuts, if any, would show up in Kilian's model as flow supply shocks, but the model provides no evidence of supply shocks being an important determinant of the real price of oil during 2003-08 (see the top panel of Figure 14).

Kilian noted one potential criticism with his results. An increase in speculative activity might raise the price of oil without causing a coincident increase in inventory accumulation, as long as the price elasticity of gasoline demand is near zero. ${ }^{41}$ Intuitively, if users of gasoline did not reduce their demands when the price rose, then a higher expected price in the future could cause a one-for-one increase in the current price. Oil refiners could then pass on this higher price with no drop in oil demand that would have otherwise caused inventories to swell. But Kilian ruled out this possibility, by noting that the price elasticities of his 14 admissible models were clearly negative. Consequently, the data support the idea that higher speculative demand would result in both higher prices today and an increase in oil inventories.

In closing, Kilian noted three policy conclusions of his work. First, the importance of flow demand shocks in the 2003-2008 period indicate that additional regulation of oil markets would have done little to prevent the price increases of those years. Second, because oil is traded in world markets, higher oil production in the United States would not be large enough to make a material difference in the price of oil. Third, when the world economy is fully revived in the wake of the the Great Recession, policymakers are likely to be confronted by a dilemma as oil prices rise again. "The only way that you're going to get out of that dilemma is either by conserving on the use of energy, or by finding some alternative source of energy," Kilian told the policymakers in attendance. "We've had a lot of discussion earlier today about how difficult that might actually be. But if you can't do that, then if the

\footnotetext{
${ }^{40}$ While the demand for inventories rose in 1990, the actual level of inventories was held down in that year by a drop in oil production, Kilian said.

${ }^{41}$ The possibility that a zero price elasticity could allow speculation to cause prices to rise without swelling inventory is discussed in Hamilton (2009). That paper points out that a low demand elasticity might make it easier for speculation to explain the 2003-2008 oil-price increase. But Hamilton (2009) also contends that a low demand elasticity is also required for higher oil demand, brought about by increased global economic activity, to drive oil prices higher.
} 


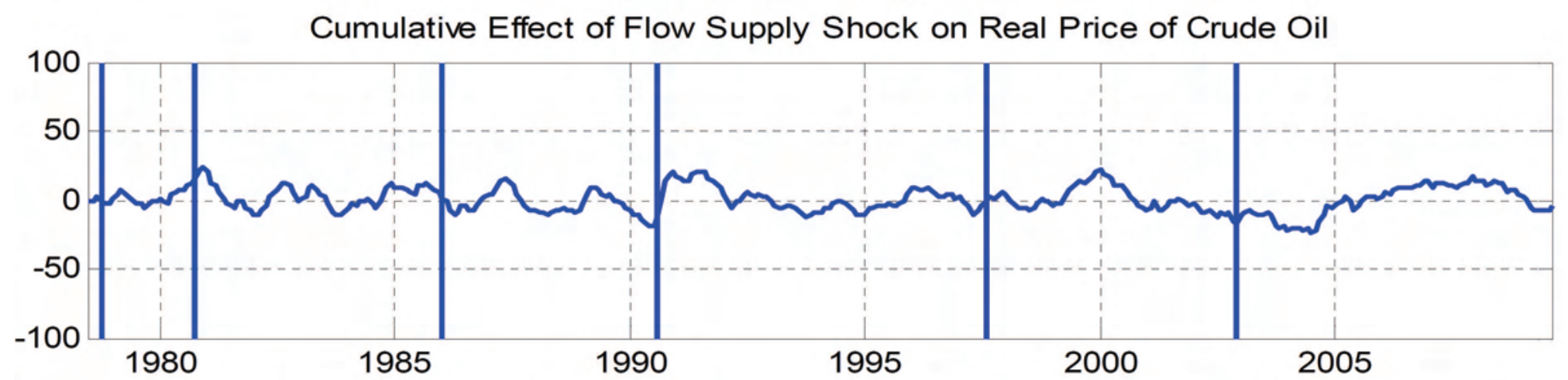

Cumulative Effect of Flow Demand Shock on Real Price of Crude Oil

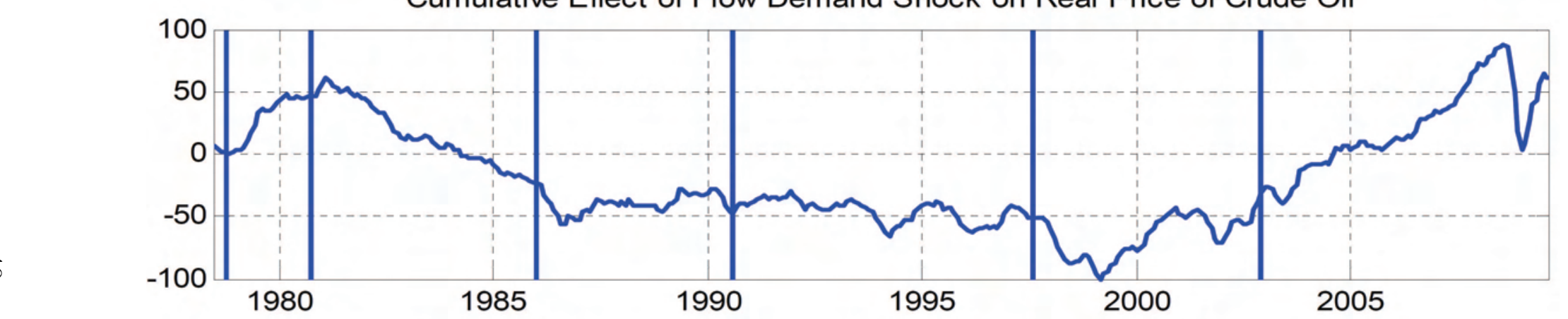

Cumulative Effect of Speculative Demand Shock on Real Price of Crude Oil

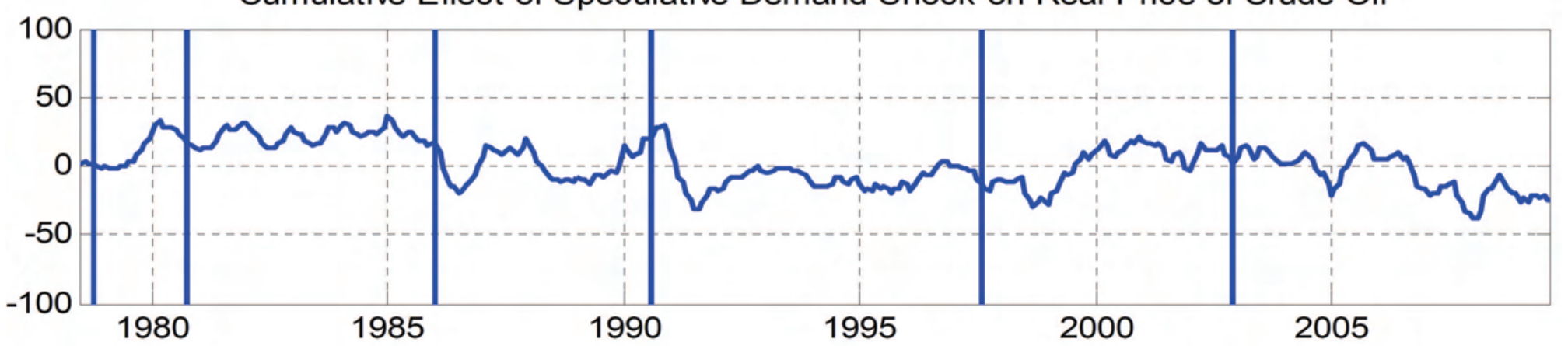

Figure 14. Cumulative Effects of Flow-Supply, Flow-Demand, and Speculative-Demand Shocks in the Kilian-Murphy Model. Each panel presents an estimate of the oil price if only that particular shock had been operational during the sample period. The vertical bars indicate major exogenous events in oil markets, notably the outbreak of the Iranian Revolution in 1978 and of the Iran-Iraq War in 1980, the collapse of OPEC in 1985.12, the outbreak of the Persian Gulf War in 1990, the Asian Financial Crisis of 1997, and the Venezuelan crisis in 2002, which was followed by the Iraq War in early 2003. In constructing the historical decomposition the first five years of data are discarded in an effort to remove any transition dynamics. The large increase in the cumulative effect in the middle panel after 2000 supports the claim that higher demand, not reduced supply or speculative shocks, caused the oil-price run-up of the mid-2000s. 
economy recovers, so will the price of oil."

In his discussion of Kilian's presentation, Mark Watson, the Howard Harrison and Gabrielle Snyder Beck Professor of Economics and Public Affairs at Princeton University, focused on some technical aspects of Kilian's econometric procedure. Most econometric procedures are "point identified," meaning that the resulting parameter estimates reflect the econometrician's best guess as to the value of the population parameters under study. Unfortunately, point identification often requires strong identifying assumptions. For example, a point-identified model of the oil market might require the assumption that monthly movements in oil prices do not depend on movements of global economic activity in the same month. By eschewing such strong identifying assumptions, researchers can deliver more robust estimates. The tradeoff, however, is that more than one set of parameter estimates is usually admissible under set-identification procedures, as is the case in the Kilian-Murphy model. The researcher must then find some way of presenting his or her results. The researcher could present the entire set of admissible models, take some sort of average over all admissible models, or select a single benchmark model out of the entire admissible set. ${ }^{42}$

Watson pointed out that, as a general matter, conveying the right amount of statistical uncertainty in set-identification techniques is not easy. Because researchers using setidentification techniques generally try to be agnostic as possible, they usually do not want to prefer one set of estimates over others in the admissible set. However, Watson noted that some common set-identification techniques can have an undesirable implication in this regard. Even though a researcher might want to weight all admissible models equally when presenting his or her results, technical details in some common set-identification procedures could imply that some models in the admissible set are given more weight than others in the final analysis of results. Thus, while set-identification techniques do not have to rely on strong identifying assumptions, it can be difficult to convey their results in a straightforward way. Kilian responded to Watson's discussion by stressing that all 14 of the admissible models from his procedure generated the same bottom-line results, making the conclusions invariant to alternative methods of summarizing them.

\footnotetext{
${ }^{42}$ As noted above, Kilian's procedure generated a set of 14 permissible models out of 5 million candidate models tested. Kilian chose to present results from a benchmark model that was chosen on the basis of the oil-demand elasticity it implied. Specifically, the oil-demand elasticity implied by the benchmark model was closest to the median oil-demand elasticity implied by all admissible models.
} 


\section{The Macroeconomic Effects of Oil-Price Shocks: An Empirical Assessment}

James Hamilton began by noting the main empirical regularity from Hamilton (1983): Recessions have generally been preceded by stark increases in the price of oil. One potential explanation is that oil prices encourage firms to economize on oil inputs and thereby reduce the amount of output that they produce. Hamilton noted that this effect should be roughly proportional to the expenditure share of oil in firm-level costs, a share that is easily observed to be too small to allow large effects of oil prices on aggregate supply. A more complicated aggregate-supply channel assumes that wages adjust in response to oil-price changes, so that higher oil prices do not reduce the amount of labor and capital used in the production process. In this more-flexible scenario, Hamilton explained, the response of the economy to higher oil prices depends critically on the elasticity of energy use with respect to the relative price of oil. Yet this channel also predicts that GDP should not change much when the relative price of oil rises, because energy use changes little in response to higher energy prices. "This whole mechanism would only matter if [energy use] were very highly elastic," Hamilton said. "So I don't find that [channel] a very plausible explanation for why oil price increases are followed by recessions."

If aggregate supply does not explain the oil-GDP relationship, then aggregate demand is the next place to look. Perhaps the simplest way to do so is to view higher oil prices as a tax that reduces the disposable incomes of consumers. When Americans are forced to pay more for imported oil, they must remit more income abroad, leaving less income to spend on domestically produced goods and services. The resulting decline in consumption reduces aggregate demand and slows GDP growth. Hamilton said that about 5 percent of consumer spending goes to energy products. So if oil prices rise by 20 percent, and if American consumers continue to purchase the same amount of energy goods as before, then a pure income channel would imply that Americans' consumption of other goods should fall by 1 percent.

To test whether this consumption response is evident in the data, Hamilton drew on a paper by Edelstein and Kilian (2009) that calculates the responses of various consumption categories to higher oil prices. ${ }^{43}$ A highly useful innovation of that paper is its normalization of consumption responses to equal 1 percent if the pure income channel explains the oil-GDP relationship. Hamilton showed that this method does indeed show a decline in consumption

\footnotetext{
${ }^{43}$ See Edelstein and Kilian (2007) for the more-expansive, working-paper version of Edelstein and Kilian (2009).
} 

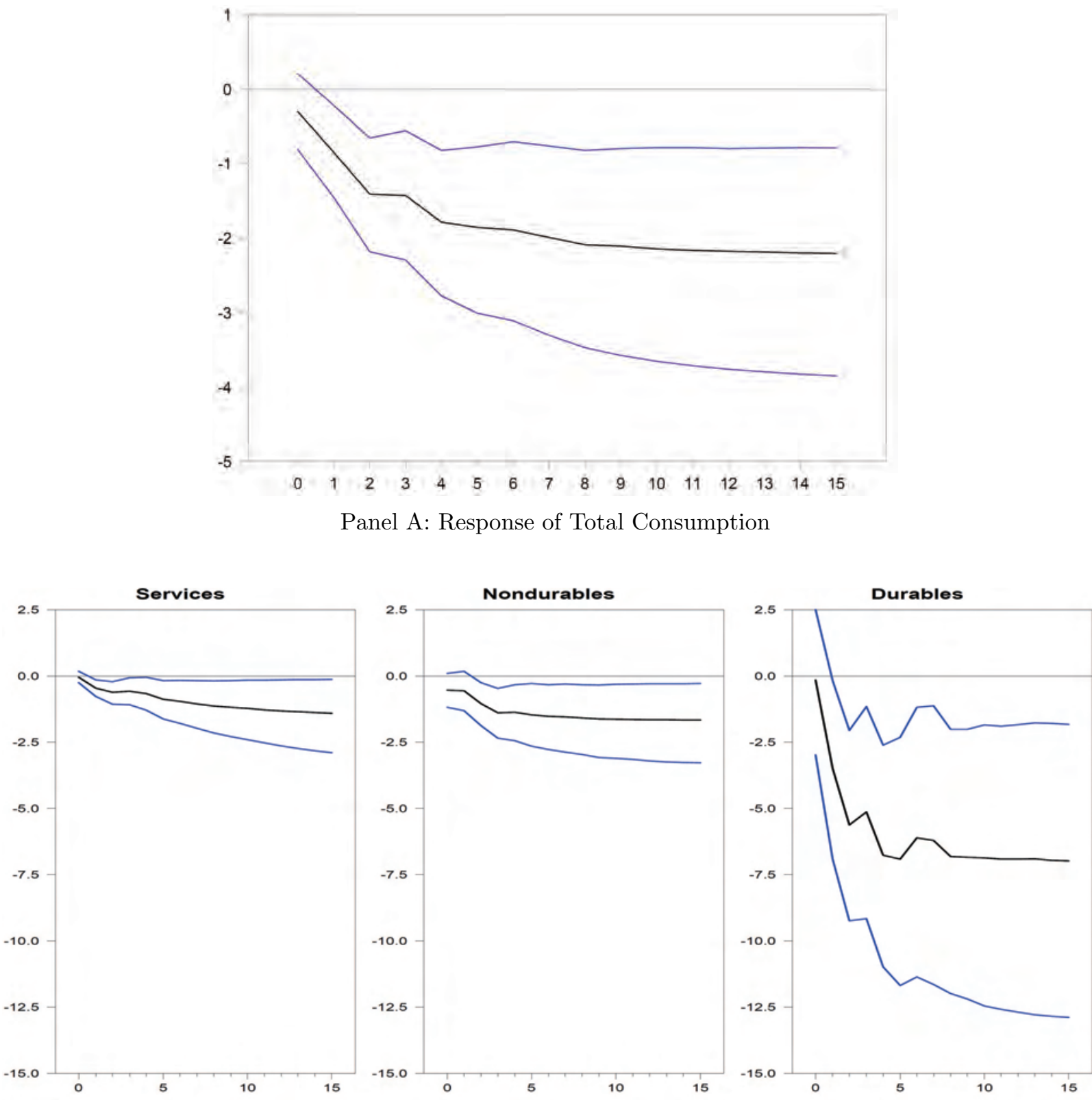

Panel B: Responses of Consumption Components

Figure 15. Consumption Responses to a Rise in Oil Prices that Reduces Consumers' Purchasing Power by 1 Percent. Panel A replicates Figure 8a in Edelstein and Kilian (2007). The three graphs in Panel B replicate Figures 8b-8d in the same paper. The sample period for each figure ends in 2006. 
after energy prices rise. But, as shown in Panel A of Figure 15, the Edelstein-Kilian method also reveals two anomalies. First, the consumption decline is much larger than the 1 percent predicted by the pure income channel. Second, the large decline in consumption is spread out over many months. In short, the consumption response to higher oil prices is both larger and more protracted than the pure income effect would predict.

To explain these anomalies, Hamilton followed Edelstein and Kilian (2009) and investigated various sub-categories of consumption, shown in Panel B of Figure 15. The declines in the consumption of services and non-durable goods are both close to the 1-percent benchmark prediction. But the decline in consumption of durable goods is much larger-more than 5 percent after six months. Hamilton further explained that much of the decline in durables consumption comes from a drop in motor vehicle sales. Moreover, the drop in motor-vehicle sales is not delayed, but instead comes within a couple of months after the energy-price increase. "So what we see in the data is that, when energy prices go up, consumers immediately cut back - substantially - their purchase of motor vehicles," Hamilton said. "And once you say that that's the basic thing in the data, you realize that this isn't just a pure income effect."

Hamilton believes that the best explanation for these findings involves consumer uncertainty. When oil prices rise, consumers wait to see whether the price increase is permanent or temporary, and whether this increase has a long-lasting impact on the business cycle. This wait-and-see attitude delays the purchase of expensive, long-lasting items that use oil as an input, such as cars. "And furthermore, if you take a Keynesian view of things, that is going to mean lower income for people in the auto sector," he said. "They may reduce their spending. And that could account for that delayed response that we see in total consumption spending and the economy." Some corroborative evidence for the importance of consumer attitudes in the oil-GDP link comes from the estimated response of consumer sentiment to oil prices. Hamilton pointed out that an increase in energy prices that reduces spending power by 1 percent also causes consumer sentiment to decline by 15 points. ${ }^{44}$

Hamilton then turned to how the oil-GDP relationship might have changed over time. Some analysts have downgraded the importance of oil-price fluctuations in recent years because of a decline in the energy share of consumption goods. Much of this decline, Hamilton said, can be explained by an income elasticity of energy demand for the United States that is less than one, which would imply that the U.S. energy-expenditure share

\footnotetext{
${ }^{44}$ The consumer sentiment index to which Hamilton referred is released monthly by the University of Michigan's Survey Research Center and the Thompson Reuters company. It is indexed to equal 100 in 1966:Q1. The quarterly average of the monthly series remained above 100 during the robust business-cycle climate of the late 1990s, topping out at 110.1 in 2000:Q1. During the most recent financial crisis, the index declined from 85.7 in 2007:Q3 to 57.7 in 2008:Q4.
} 
should drop as America becomes richer. ${ }^{45}$ But Hamilton also noted that the energy share in consumption expenditures has not been on a completely stable downward path. When energy prices rise abruptly, consumers try to purchase the same physical quantities of energy goods as they had before, causing the energy share of consumption to rise precisely at the time that higher energy prices adversely affect the economy. For example, after the substantial oil-price increases of the mid-2000s, the energy share in consumption approached levels from the 1970s, Hamilton said.

Hamilton noted that the relative decline of the auto industry had led some to argue that the importance of oil prices in economic fluctuations had fallen over time. To address this issue, Hamilton drew on a paper by Ramey and Vine (2010), which argues that the response of the economy to oil shocks has been remarkably stable over time. ${ }^{46}$ The Ramey-Vine paper replicates the well-known finding that goods production has become less important in the U.S. economy relative to the the production of services. However, the share of U.S. GDP accounted for by the motor vehicle industry has declined only modestly, from about 4.0 percent in the 1967-85 period to about 3.3 percent in the 1986-2009 period. Moreover, the auto sector has remained quite cyclical, so its share of overall GDP volatility has remained substantial. ${ }^{47}$ "Autos are still very important for the U.S. economy, and in particular, automobiles are still a very important part of overall GDP volatility," Hamilton said. "So I think that people have overdone a little bit the extent to which the U.S. economy is immune to movements in oil prices today."

Hamilton then contended that the behavior of the U.S. economy during the opening months of the Great Recession indicated that oil prices matter for economic fluctuations. He conceded that upheavals in financial markets, sparked in part by the collapse of Lehman Brothers in September 2008, were the main reason the Great Recession was more serious than previous downturns. But early in the recession, auto sales declined significantly, with the brunt of the reduction borne by low-mileage sport-utility vehicles and the like. Imports of cars actually rose, Hamilton said, though imports of less-fuel-efficient vehicles fell along with their domestically produced counterparts. "I think that it's very clear that one of the key things hitting the U.S. auto sector in the first year of the recession was not [financial in origin]," Hamilton said. "It's a specific response to what was going on with energy prices, and how consumers were responding to them in a pretty traditional way."

To further support this claim, Hamilton presented some econometric evidence indicating

\footnotetext{
${ }^{45}$ See also the discussion of the energy ladder depicted in Figure 11.

${ }^{46}$ Ramey and Vine (2010) note that stability is apparent if one accounts for the additional economic costs of shortages and rationing in the 1970s.

${ }^{47}$ According to Ramey and Vine (2010), the auto industry accounted for about 38.1 percent of overall GDP volatility in the 1967-1985 period. In the 1986-2009 period, this share was 24.9 percent.
} 


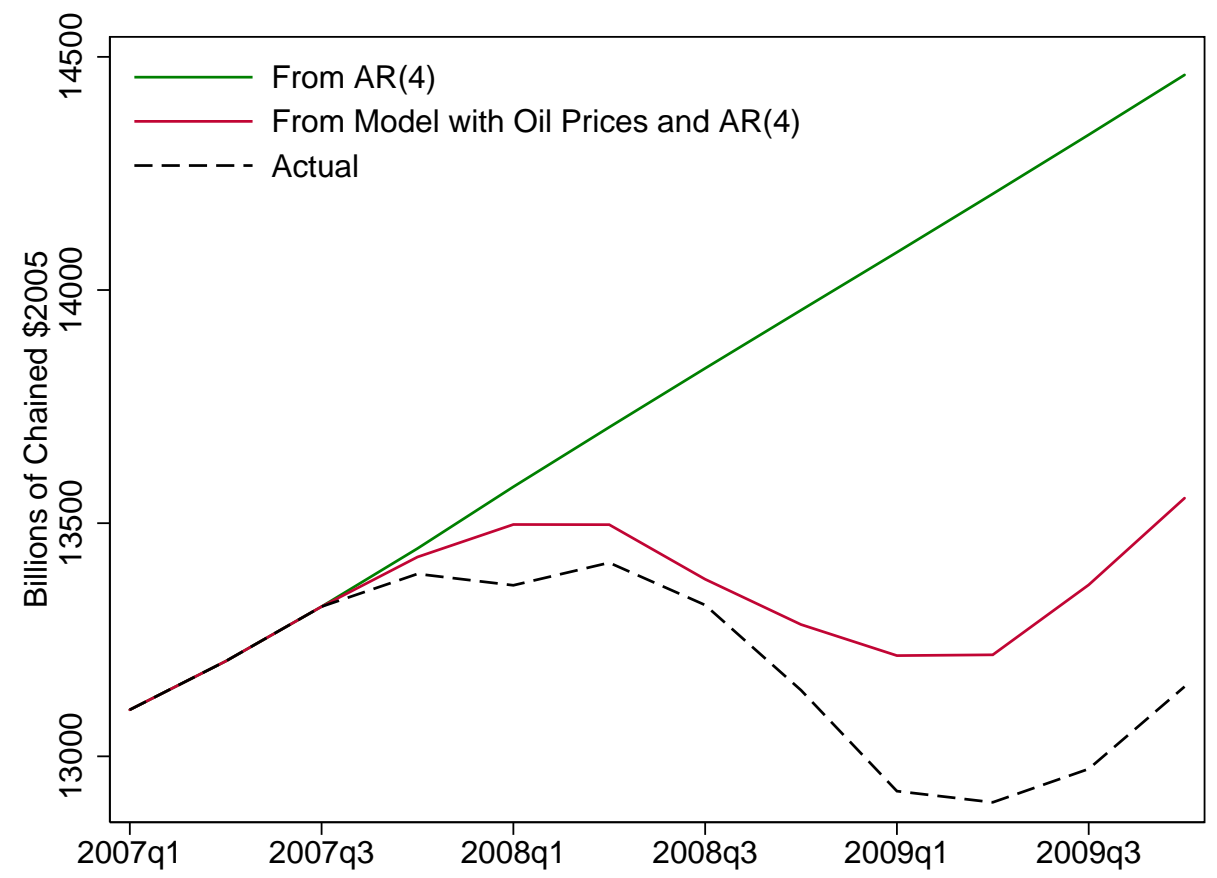

Figure 16. Dynamic Simulations of Real GDP. Simulations begin in 2007:Q4. The model with oil prices is an updated estimate of Equation 3.8 of Hamilton (2003), which projects quarterly real GDP growth rates on four of its own lags and four lagged oil-shock variables. The shock variables are designed to reflect growth in oil prices above recent peaks, and are set to zero if the current oil price is lower than its maximum over the preceding 12 quarters.

that in the early months of the recession, the behavior of GDP was consistent with what would have been predicted after the large run-up in oil prices, as shown in Figure 16. The same is true of consumption, motor-vehicle purchases, and consumer sentiment. Relating oil prices to well-known problems in the housing market, Hamilton noted that higher gasoline prices made the purchase of homes in outlying areas less attractive, so even housing may have been adversely affected by energy markets.

"What made this the 'Great Recession' were financial problems," Hamilton concluded. "But I do think that oil prices unambiguously made a contribution to the first year of the recession. I think you can make a pretty good case that oil prices were what turned slow growth into what we call a recession. And once you go that far, then you've got to agree that higher oil prices could have only exacerbated the other problems." 48

The discussant for Hamilton's presentation was Ethan Harris of Bank of America/Merrill Lynch, who walked the audience through the six oil-price episodes he had personally studied during his career. The first episode was the sharp drop in oil prices in 1986. Then working at the New York Fed, Harris believed that the price decline would raise consumption spending

\footnotetext{
${ }^{48}$ For additional discussion on the origins and aftereffects of the oil shock of 2007-08, see Hamilton (2009). A general summary of the relationship between oil and the macroeconomy is found in Hamilton (2008).
} 
through a type of pure income effect examined by Hamilton. What happened instead was an economic slowdown, due in large part to a drop in the construction of nonresidential structures (such as drilling rigs) in the oil-patch states. To Harris, this episode provides a clear example of the inherent complexity in the oil-GDP relationship, a main theme of his remarks. "There was a nonlinearity here," Harris said. "Oil-price movements were important enough to really matter in the oil patch, so there was a big recession there. But due to lags, or threshold effects, or whatever, the price decline wasn't big enough to help the rest of the economy. So we ended up with a growth slowdown, rather than a pickup in growth."

Harris's second episode was the spike in oil prices that took place after Iraq's 1990 invasion of Kuwait. Harris and his Fed colleagues believed that this increase would not be serious enough to tip the economy into recession. But the increase occurred after a monetary tightening and the savings-and-loan crisis had slowed the economy. To Harris, the price increase provides an example of how psychological framing can influence the effects of oil-price changes. Consumers probably remembered the deleterious effect of the 1970s' oil shocks and downgraded their economic outlooks when oil prices jumped. Consumption spending then fell and the economy slowed. "I think that what happened in 1990 was an oil shock that should have had a moderate negative impact on the economy had a much deeper impact," Harris said. "The average person remembered the oil shocks of the 1970s and thought, 'When oil prices go up because something bad happened in the Middle East, then we're in serious trouble.' And I think that that collapse in confidence was an example of [psychological] framing."

The third episode, which took place after Harris had left for Wall Street, was the collapse of oil prices in the late 1990s. This decline probably helped offset the negative effects on the U.S. economy stemming from the Asian crisis, but neither the oil-price decline nor the Asian crisis had large effects in and of themselves. The fourth episode was the steady rise in oil prices from 2002 through 2006. Like Kilian in the previous session, Harris argued that this increase resulted from ongoing increases in the demand for oil, coupled with only moderate increases in supply. What makes this episode particularly interesting, Harris said, is that the price increase should have been large enough to slow the U.S. economy during this time, given the previously estimated relationship between oil prices and GDP. But U.S. economic growth continued until 2007.

To Harris, this continued growth was another example of the nonlinearities inherent in the oil-GDP relationship. He drew on the apocryphal story of a frog in a pot of water that is cool at first, but slowly grows warmer until it boils. "As the heat goes up, the frog doesn't pay too much attention, until it's too late," Harris said. "I felt at the time that, given the 
state of the economy, with the recovery [from the 2001 recession] going on, people didn't care if it took a little more money to fill up their 'mobile mansions,' and they just kind of ignored the price increases." The deeper lesson may be that a slow run-up in oil prices may not meet a threshold for having adverse effects on GDP.

The next episode was the rapid run-up in oil prices in 2007-08. Harris said that cracks in the real economy had appeared by 2008, "so I agree with Jim [Hamilton] wholeheartedly. The oil shock was a big deal — not as important as Lehman Brothers - but it had a huge impact." As evidence, Harris pointed to the September 2008 employment report, which was based on data gathered immediately before the Lehman Brothers bankruptcy. This report showed large job losses, indicating that the economy was quite weak even before Lehman went under. ${ }^{49}$ The sixth and final episode Harris discussed was the drop in oil prices that took place in mid-2008, when global economic weakness became evident. Despite the windfall to consumers that stemmed from lower oil prices, credit problems and rising unemployment caused consumption to contract, not increase.

"To me, the lessons of history are that there are a lot of nonlinearities and identification issues that we have to pay very close attention to," Harris said. "I think that's why it's such a challenge to model oil and its impact on the economy. Whether all these stories are correct or not, there are elements of these nonlinearities in the way that the economy responds."

Harris concluded with a discussion of the relationship between oil-price changes and monetary policy. A theme in these remarks is that the Fed has built up a "reservoir of trust and anti-inflation credibility," which allows it to be flexible when oil prices rise. A temporary oil-price spike might move headline inflation higher, even if the core inflation rate shows no increase in the economy's underlying inflationary momentum. When a divergence between headline and core inflation occurs, a credible Fed can hold off on raising interest rates without risking an increase in inflationary expectations, so long as people believe that the Fed is committed to low and stable inflation over the long term, Harris said.

As a case in point, Harris applauded the Fed's decision to reduce the federal funds rate to only 1 percent in the wake of the 2001 recession. Even though oil prices were also headed higher after 2001, the overarching goal of the Fed should have been to prevent a doubledip recession, which remained a distinct possibility at the time. Harris also commended the Fed's decision to lower interest rates in early 2008 as the real economy weakened, even though oil prices were then headed higher. "You have anti-inflation credibility for a reason," Harris said of the Fed, "and that's to use it when you're in an environment where there's a

\footnotetext{
${ }^{49}$ Revised data indicate that the economy lost 434,000 payroll jobs in September 2008. Job losses would rise to 509,000 in October and exceed 700,000 in each of the first three months of 2009.
} 
serious downside risk to growth. And this was a good use of anti-inflation credibility."

Harris was less supportive of the slow pace of interest-rate increases that began in 2004, after the recovery from the 2001 recession had attained a firmer footing. He claimed that the tepid rate of monetary tightening after that recession caused the overall price level to rise higher than it should have, undermining Fed credibility. Moreover, Harris said that the Fed should have realized that interest-rate increases were not preventing financial conditions from loosening in the mid-to-late 2000s, thanks to the growing bubble in the housing market.

"I don't buy this idea that we can't identify bubbles," he added. "I think in a probabilistic sense, bubbles are identifiable, particularly when you've got people who are actually saying that they are speculating in the housing market, and ... when people are investing and taking out mortgages that are only justifiable in a rising home-price environment. To me, that's a bubble if there ever was one."

\section{Conclusion: Some Outstanding Questions}

As noted in the Introduction, the conference produced four major conclusions:

1. Oil prices are likely to remain high for the foreseeable future;

2. Predictions for oil prices are highly uncertain, as they have been since the 1970s;

3. Economists do not agree on whether the use of oil as a financial asset has affected oil prices; and

4. Economists concur that oil prices continue to have sizable effects on the U.S. economy.

There was a general consensus that rapid growth in oil demand from China and other developing countries (with OECD demand remaining stable), combined with flat to declining supplies from non-OPEC producers, will leave the OPEC cartel with considerable market power. As Hobbs and Dvir agreed, when access to oil supplies or spare production capacity is limited, demand or supply shocks lead to volatile - and often higher - oil prices. Possible sources of such shocks, and thus of forecast uncertainty, include business cycle, technological, and political developments of the kind seen in the past several months. First, the accident at Japan's Fukushima Daiichi nuclear plant caused Japan and Germany to delay or scotch plans for significant increases in the use of nuclear energy as an alternative to oil; other countries seem likely to follow suit. Second, while Libya is currently the only OPEC member embroiled in the spreading turmoil of the Arab Spring, these unforeseen uprisings have stirred questions about the stability of the entire Middle East and have undoubtedly also contributed to the recent increase in the price of WTI crude to almost $\$ 115$ per barrel. 
Finally, and probably most importantly, has come the growing recognition that technological developments have turned shale gas into "a game changer" not only for the U.S. natural gas market but also for the world gas market. Indeed, according to a report released by the EIA in April 2011, adding newly identified shale gas reserves to other gas resources increases world total recoverable gas reserves by more than 40 percent (Energy Information Administration 2011c). ${ }^{50}$

Because natural gas is distributed differently and somewhat more widely than oil, encouraging development of this alternative source of energy represents one feasible, if modest, step towards the energy independence advocated by many policymakers. Unfortunately, however, new supplies of natural gas are of limited use in the transportation sector, which remains almost entirely dependent on liquid fuels. Indeed, as described above, 70 percent of the U.S. liquid fuels supply goes to the transportation sector, which the EIA expects to be almost as dependent on oil-based fuels in 2035 as it is today. As the morning sessions of the oil conference made clear, in other words, until the global transportation sector figures out how to sever its ties to gasoline, oil prices are likely to remain high and volatile. Because the social benefit of weaning the transportation sector from oil exceeds the private benefit, additional government intervention to hasten the transition is likely warranted.

By contrast with the discussion about the likely course of oil prices, the symposium discussion on the growing use of oil as a financial asset produced more limited agreement but suggested a few policy implications nevertheless. First, the conference participants generally agreed that the growing use of oil and other commodities as financial assets has increased the depth, liquidity, and cointegration of the related derivatives markets and that the resulting improvement in the price discovery process has benefitted all market participants. In addition, financialization has also brought new, non-traditional investors with non-traditional goals into the commodity markets, thereby changing the determinants of oil prices from the supply and demand for oil as an input to production to the supply and demand for oil as an input to production and as an instrument for managing portfolio and exchange rate risk. However, the effects of this change remain subject to debate, with some observers arguing that financialization likely adds to the volatility - or even changes the level - of oil prices, while others see no such effect. Clarifying the impact of financialization on oil prices remains a major research issue requiring better identification and measurement of expected future oil prices and related investment activity.

\footnotetext{
${ }^{50}$ In the United States, shale gas production has increased from 0.4 trillion cubic feet in 2000 to 4.9 trillion cubic feet in 2010, or 23 percent of U.S. dry gas production. Other countries where shale gas development may prove attractive include China, Argentina, Brazil, South Africa, Canada, Mexico, Australia, France, and Poland.
} 
Turning to the lessons for regulators, it seems clear from the May 6, 2010 "flash crash" that under stressed conditions, automated execution of a large sell order without reference to price or speed of execution can lead to disorderly conditions and should be discouragedpossibly by limiting the size of an order or by requiring brokers and customers to make non-disruptive trades. In addition, however, market participants concerned about the conditions that led to the evaporation of market liquidity in the flash crash have pointed to data-feed problems, the lack of clarity regarding the rules for canceling trades, and uncoordinated pauses in some exchanges while others continued at full speed. Because securities and derivatives markets are interconnected, these markets require compatible regulation regarding pauses and circuit breakers, while data collection and dissemination should be harmonized across markets in terms of availability, conventions, and timeliness. Regulations also need to be clear, objective, and transparent lest they aggravate disorderly market conditions. More generally, finally, because rising inventory accumulation often signals the development of bubble conditions, commodity markets would benefit from more timely and complete information on inventories (including floating inventory and non-OECD stocks) as well as more detailed data on futures and OTC transactions. The Dodd-Frank Act is spurring efforts to address many of these issues.

By contrast with the lack of consensus regarding the impact of the financialization of oil markets, the conference participants had no trouble agreeing on the empirical regularity that large oil supply shocks generally precede U.S. recessions and tend to have a larger and more extended negative impact on the economy than the importance of oil in consumption or production would suggest. Hamilton attributes the disproportionate outcome to an accompanying surge in uncertainty about future oil prices, which leads to an immediate collapse in auto sales and a more extended recession in the auto industry. As Hamilton pointed out, the auto industry continues to play a significant role in the U.S. economy and, even more, in U.S. economic fluctuations. Nevertheless, while the generalized regularities surrounding oil price shocks seem clear, analyzing the impact of specific oil shocks in real time remains a complex challenge given the nonlinearities, asymmetries, and threshold effects that were the focus of Ethan Harris's remarks. Gaining a more nuanced understanding of these complexities remains another promising area for additional research.

Surprisingly, the conference participants devoted relatively little attention to how rising oil prices affect inflation and inflation expectations - an issue of key importance to monetary policymakers in 2008 and again in mid-2011. This silence likely attests to the participants' confidence that this impact remains quite limited as long as the monetary authority has credibility and inflation expectations remain anchored. Indeed, Harris likely spoke for the other participants as well when he argued that the Fed has created a "reservoir of anti- 
inflation credibility" that allows it to delay raising interest rates when an oil shock produces a gap between core and total inflation. He contended that a credible Fed can avoid raising interest rates and aggravating the negative impact of an oil price increase on output and employment without risking an increase in inflation expectations as long as people believe that the Fed is committed to low, stable inflation over the long term. As Boston Fed President Eric Rosengren pointed out in a recent speech, this high-credibility scenario describes the prevailing experience since the mid-1980s (Rosengren 2011). However, in the low-transparency, low-credibility world of the 1970s and early 1980s, oil shocks did lead to a rise in inflation expectations, wage pressures, and a period of high core, as well as total, inflation. Thus, even though current medium to long-term inflation expectations remain well anchored, Rosengren argued that the Fed must continue to monitor inflation dynamics very closely to make sure that inflation expectations do not become unmoored as they did in the 1970s. In this context, additional research to improve economists' understanding of the nonlinearities and asymmetries in the relationship between oil prices and inflation dynamics could be very useful. 


\section{References}

Alquist, Ron, Lutz Kilian, and Robert J. Vigfusson. 2011. "Forecasting the Price of Oil." Prepared for the Handbook of Economic Forecasting, Graham Elliott and Allan Timmerman, eds. Available at http://www-personal.umich.edu/ lkilian/hdbk050511.pdf.

Baumeister, Christiane, and Lutz Kilian. 2011. "Real-Time Forecasts of the Real Price of Oil." Available at http://www-personal.umich.edu/ lkilian/bk051411.pdf.

BP, PLC. 2010. BP Statistical Review of World Energy. Available at http://bp.com/ statisticalreview.

Buyuksahin, Bahattin, Michael S. Haigh, Jeffrey H. Harris, James A. Overdahl, and Michel A. Robe. 2008. "Fundamentals, Trader Activity and Derivative Pricing." SSRN eLibrary. Available at http://ssrn.com/paper $=966692$.

Dvir, Eyal, and Kenneth S. Rogoff. 2009. "Three Epochs of Oil." National Bureau of Economic Research Working Paper No. 14927. Available at http://www.nber.org/papers/ w14927.

Edelstein, Paul, and Lutz Kilian. 2007. "Retail Energy Prices and Consumer Expenditures." Centre for Economic Policy Research Discussion Paper No. 6255. Available at http:// sitemaker.umich.edu/pedelstein/files/ek040707a.pdf.

Edelstein, Paul, and Lutz Kilian. 2009. "How Sensitive Are Consumer Expenditures to Retail Energy Prices?" Journal of Monetary Economics 56(6): 766-779.

Energy Information Administration. 2010. "International Energy Outlook: 2010." Tech. rep. U.S. Energy Information Administration. Available at http://www.eia.gov/oiaf/ieo/.

Energy Information Administration. 2011a. "Annual Energy Outlook: 2011." Tech. rep. U.S. Energy Information Administration. Available at http://www.eia.doe.gov/forecasts/ aeo/index.cfm.

Energy Information Administration. 2011b. "Short-Term Energy Outlook: May 2011." Tech. rep. U.S. Energy Information Administration. Available at http://www.eia.doe. gov/emeu/steo/pub/contents.html.

Energy Information Administration. 2011c. "World Shale Gas Resources: An Initial Assessment of 14 Regions Outside the United States." Tech. rep. U.S. Energy Information Administration. Available at http://www.eia.gov/analysis/studies/worldshalegas/pdf/ fullreport.pdf.

Gorton, Gary, and K. Geert Rouwenhorst. 2006. "Facts and Fantasies about Commodity Futures." Financial Analysts Journal 62(2): 47-68.

Haigh, Martin. 2008. "Shell's World Energy Model." Paper presented at the September 2008 British Institute of Energy Economics Conference, Oxford, UK. Available at http: //www.biee.org/downloads/index.php. 
Hamilton, James D. 1983. "Oil and the Macroeconomy since World War II." The Journal of Political Economy 91(2): 228-248.

Hamilton, James D. 2003. "What is an Oil Shock?" Journal of Econometrics 113: pp. 363-398.

Hamilton, James D. 2008. "Oil and the Macroeconomy." In The New Palgrave Dictionary of Economics, eds. Steven N. Durlauf and Lawrence E. Blume. Basingstoke: Palgrave Macmillan, 2nd ed. Available at http://www.dictionaryofeconomics.com/article? id=pde2008_E000233.

Hamilton, James D. 2009. "Causes and Consequences of the Oil Shock of 2007-08." Brookings Papers on Economic Activity 2009: 215-283.

Hamilton, James D. 2010. "Nonlinearities and the Macroeconomic Effects of Oil Prices." University of California at San Diego Working Paper. Available at http://dss.ucsd.edu/ jhamilto/oil_nonlinear_macro_dyn.pdf.

Hamilton, James D. 2011. "Historical Oil Shocks." University of California San Diego Working Paper. Available at http://dss.ucsd.edu/ jhamilto/oil_history.pdf.

Harris, Jeffrey H., and Bahattin Buyuksahin. 2009. "The Role of Speculators in the Crude Oil Futures Market." SSRN eLibrary. Available at http://ssrn.com/paper=1435042.

Interagency Task Force on Commodity Markets. 2008. "Interim Report on Crude Oil." Available at http://www.cftc.gov/ucm/groups/public/@newsroom/documents/ file/itfinterimreportoncrudeoil0708.pdf.

Kilian, Lutz, and Daniel Murphy. 2009. "Why Agnostic Sign Restrictions are Not Enough: Understanding the Dynamics of Oil-Market VAR Models." University of Michigan Working Paper. Available at http://www-personal.umich.edu/ lkilian/km080210.pdf.

Kilian, Lutz, and Daniel Murphy. 2010. "The Role of Inventories and Speculative Trading the Global Market for Crude Oil." University of Michigan Working Paper. Available at http://www-personal.umich.edu/ /kilian/km051010.pdf.

Kilian, Lutz, and Robert J. Vigfusson. 2010. "Are the Responses of the U.S. Economy Asymmetric In Energy Price Increases and Decreases?" University of Michigan Working Paper. Available at http://www-personal.umich.edu/ lkilian/kv032310.pdf.

Ramey, Valerie A., and Daniel J. Vine. 2010. "Oil, Automobiles, and the U.S. Economy: How Much Have Things Really Changed?" Forthcoming in the NBER Macroeconomics Annual (2010). Available at http://econ.ucsd.edu/ vramey/research/Ramey_ Vine_NBER_2010Macroannual.pdf.

Rosengren, Eric S. 2011. "A Look Inside a Key Economic Debate: How Should Monetary Policy Respond to Price Increases Driven by Supply Shocks?" Remarks to the Massachusetts Chapter of NAIOP, the Commercial Real Estate Development Association. May 4. Available at http://www.bos.frb.org/news/speeches/rosengren/2011/ 050411/index.htm. 
Stoll, Hans R., and Robert E. Whaley. 2009. "Commodity Index Investing and Commodity Futures Prices." SSRN eLibrary. Available at http://ssrn.com/paper=1478195.

Tang, Ke, and Wei Xiong. 2010. "Index Investment and Financialization of Commodities." SSRN eLibrary. Available at http://ssrn.com/paper=1455724.

U.S. Commodity Futures Trading Commission and U.S. Securities and Exchange Commission. 2010. "Findings Regarding the Market Events of May 6, 2010: Report of the Staffs of the Commodity Futures Trading Commission and the Securities and Exchange Commission to the Joint Advisory Committee on Emerging Regulatory Issues." September 30, 2010. Available at http://www.sec.gov/news/studies/2010/marketevents-report.pdf. 